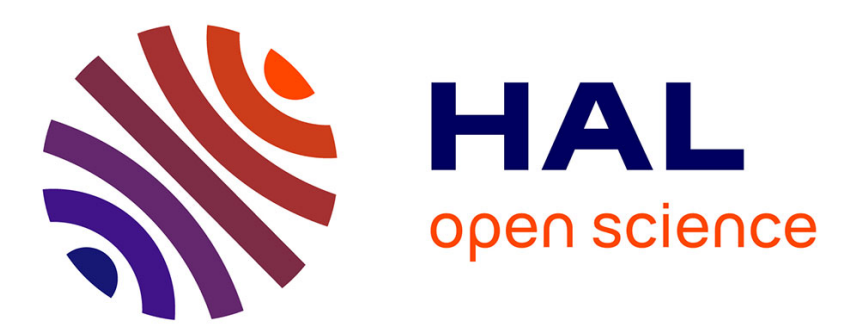

\title{
The active space debris removal mission RemoveDebris. Part 2: in orbit operations
}

Guglielmo Aglietti, Ben Taylor, Simon Fellowes, Thierry Salmon, Ingo Retat, Alexander Hall, Thomas Chabot, Aurélien Pisseloup, Christopher M. Cox, Ali Zarkesh, et al.

\section{To cite this version:}

Guglielmo Aglietti, Ben Taylor, Simon Fellowes, Thierry Salmon, Ingo Retat, et al.. The active space debris removal mission RemoveDebris. Part 2: in orbit operations. Acta Astronautica, 2020, 168, pp.310-322. 10.1016/j.actaastro.2019.09.001 . hal-02286751

\section{HAL Id: hal-02286751 \\ https://hal.inria.fr/hal-02286751}

Submitted on 13 Sep 2019

HAL is a multi-disciplinary open access archive for the deposit and dissemination of scientific research documents, whether they are published or not. The documents may come from teaching and research institutions in France or abroad, or from public or private research centers.
L'archive ouverte pluridisciplinaire HAL, est destinée au dépôt et à la diffusion de documents scientifiques de niveau recherche, publiés ou non, émanant des établissements d'enseignement et de recherche français ou étrangers, des laboratoires publics ou privés. 


\title{
The active space debris removal mission RemoveDebris. Part 2: in orbit operations
}

\author{
Guglielmo S. Aglietti' Ben Taylor, Simon Fellowes \\ Surrey Space Centre, University of Surrey, Guildford, UK \\ Thierry Salmon \\ Ariane Group, Bordeaux, France \\ Ingo Retat ${ }^{a}$, Alexander Hall ${ }^{b}$, Thomas Chabot ${ }^{c}$, Aurélien Pisseloup ${ }^{c}$ \\ Airbus: ${ }^{a}$ Bremen, Germany; ${ }^{b}$ Stevenage, UK; ${ }^{c}$ Toulouse, France \\ C. Cox, A, Zarkesh, A Mafficini, N. Vinkoff, K. Bashford \\ Surrey Satellite Technology Limited (SSTL), Guildford, UK \\ Cesar Bernal ${ }^{f}$, François Chaumette ${ }^{g}$, Alexandre Pollini ${ }^{h}$, Willem H. Steyn ${ }^{i}$

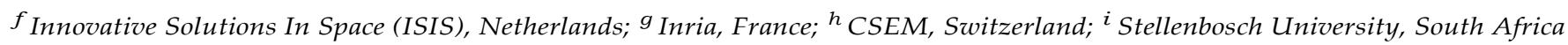

\begin{abstract}
This is the second of two companion papers that describe the development of the RemoveDEBRIS space mission. This second article describes the in-orbit operations that were performed to demonstrate technologies to be used for the active removal of space debris, whereas the first paper described the development of the satellite's hardware.

The RemoveDebris mission has been the world's first Active Debris Removal (ADR) mission to successfully demonstrate, in orbit, some cost effective technologies, including net and harpoon capture; and elements of the whole sequence of operations, like the visionbased navigation.

The satellite was launched the $2^{\text {nd }}$ of April 2018, to the International Space Station (ISS) and from there, on the $20^{\text {th }}$ of June 2018 , was deployed via the NanoRacks Kaber system into an orbit of $405 \mathrm{~km}$ altitude.

During the mission, two $2 \mathrm{U}$ CubeSats have been released by the mothercraft platform as artificial debris targets, to demonstrate net capture and cameras to be used for vision based navigation. Harpoon capture has been demonstrated by deploying a target and then firing at it a harpoon tethered to the platform. The various phases of the missions have been monitored using relevant telemetry and video cameras, and this paper reports the results of the various demonstrations.
\end{abstract}

Keywords: space debris, debris removal, ADR, deorbiting, net, harpoon, vision-based navigation, dragsail

\section{INTRODUCTION}

The background to the development of the RemoveDEBRIS mission, is discussed in detail in [1], [2] and the companion article [3] to this paper, where the design and testing of the spacecraft hardware, is also described. Various updates on the development of the mission were given periodically at the leading international conferences [4], [5], [6], [7] and [8]. To avoid repetitions, this article focuses on the in-orbit operations, and this brief introduction puts the work into context.

*Corresponding Author. Tel.: +44 (0)1483 684317

Email addresses: g.aglietti@surrey.ac.uk,

URL: www.surrey.ac.uk/ssc/

${ }^{1}$ Principal Investigator, Professor of Spacecraft Engineering
With future mega-satellite constellations being deployed, where hundreds to thousands of satellites are going to be launched into orbit (e.g. Oneweb or SpaceX' Starlink), to maintain under control the quantity of spacedebris, has become an issue of paramount importance [9].

A coherent strategy, along with technological and platform developments, is needed for the de-orbiting, re-orbiting, or servicing satellites, in particular considering the advent of such constellations. The issue of the space debris and related mitigation strategies is receiving growing attention [10], [12], and a variety of concepts have been proposed, see for example [13] and [14]. In this context, RemoveDebris has been the first space mission to demonstrate technologies for the active removal of space debris. 
Cost will be decisive factor in determining the future of ADR (e.g. [15] [16]) Hence, developing the mission concept, particular emphasis has been placed on minimizing the cost, and this has been a crucial element in the selection of the technologies that have been demonstrated and in the decision to launch the craft via the ISS.

The development of the hardware has met various challenges which related to its launch ([17] [18][19], from technical issues, for example, related to the exact definition of the launch vibration environment and appropriate levels for testing, to the need to comply with the ISS safety regulations, undergoing the various levels of the NASA safety process. For example, items such as the Cold Gas Generators (CGG) and the platform battery presented some concerns, the first related to the device incorporating a pressurized container and the nature of the chemicals in the device, the latter due to its size and capacity. CGG were used in all the inflatable structures (DSAT\#1 and DragSail)) and for the harpoon, and were an essential part of the design. Beside descriptions of all the chemicals and their quantity, the team had to demonstrate that that there were three electrical inhibits for the activation of the devices, which made accidental activation not credible. For the battery, because for the exact model that was used on the RemoDEBRIS platform, no test results were available to reassure against the possibility of a thermal runway, a new test battery had to be produced to demonstrate battery safety under thermal runaway conditions.

These are just examples that suggest that early engagement with the launch authorities facilitates the process as the appropriate requirements can be built in the design, rather than retrofitted, as this produces further costs and potential delays.

Nanorack provided technical guidance and logistical support for all the operation related to transportation to the launch site, up to release in orbit using the ISS robotic arm equipped with the KABER interface.

Table 1: RemoveDebris On-orbit operations responsibilities.

${ }^{\dagger}$ vision-based navigation

\begin{tabular}{l|l} 
Partner & Responsibility \\
\hline SSTL & $\begin{array}{l}\text { Mission Command \& Control, } \\
\text { Commissioning - LEOP }\end{array}$ \\
\hline Ariane Group & System Engineering \\
\hline $\begin{array}{l}\text { Airbus Germany } \\
\text { (support from SSC) }\end{array}$ & Net \\
\hline $\begin{array}{l}\text { Airbus France (support } \\
\text { from CSEM Inria) }\end{array}$ & $\begin{array}{l}\text { Overall VBN }{ }^{\dagger} \text { experiment } \\
\text { and algorithms }\end{array}$ \\
\hline $\begin{array}{l}\text { Airbus UK (support } \\
\text { from SSC) }\end{array}$ & Harpoon \\
\hline SSC & DragSail \\
\hline
\end{tabular}

Once in orbit, mission control was performed by SSTL, using their ground station in Guildford, and for each of the demonstrations, the institution in charge of the demonstration provided support and guidance, as reported in Table 1.

\section{I.1. Paper Structure}

Sections 2 describes the operations from the packing of the satellite at the end of the AIT to its release in orbit and satellite commissioning. Sections from 3 and 6 describe the four demonstrations, Net Capture, VBN, Harpoon capture and DragSail respectively. For each demonstration the salient events are described and overall outcomes discussed. Finally, Section 7 concludes the paper and outlines key contributions to the field.

\section{FROM LAUNCH TO SATELLITE COMMISSIONING}

\section{II.1. Launch}

RemoveDEBRIS, complete with its protective panels (see Figure 1), was accommodated inside a foam clamshell (Figure 2), and for launch the craft in its clamshell were accommodated within soft a Cargo Transfer Bag (CTB), strapped to the rack sidewall of Dragon capsule (see Figure 3). The capsule is pressurized and this launch configuration provides a soft ride since the platform is not hard mounted to the launcher.

The launch was part of the $14^{\text {th }}$ Space X CRS (Commercial Resupply Service) to the ISS, and the capsule was launched on the 2 April 2018 at 20:30 UTC on a Falcon 9 Full Thrust rocket from Cape Canaveral Air Force Station Space Launch Complex.

The decision to launch the satellite using a commercial resupply mission to the ISS and released in orbit by the ISS robotic arm, rather than a traditional launch, directly in orbit using any of the available launch opportunities (e.g. as a piggy back payload) was taken for two reasons. One concerned the safety of the mission, as the low altitude of the injection point in orbit guaranteed a relatively rapid deorbiting of all the objects. In particular the predictions reported in Figure 4 show that also in case of a malfunction of the de-orbit sail the craft should reenter the atmosphere in $\sim 120$ weeks, (i.e. well within the 25 year guideline).

The second reason was commercial, as the service offered by Nanorack via the ISS was at a price lower than the other opportunities available at the time.

The Dragon capsule reached the ISS two days after launch, the 4th of April and was captured by Canadarm2 at 10:40 UTC (see Figure 4) and was berthed to the Harmony module at 13:00 UTC. 


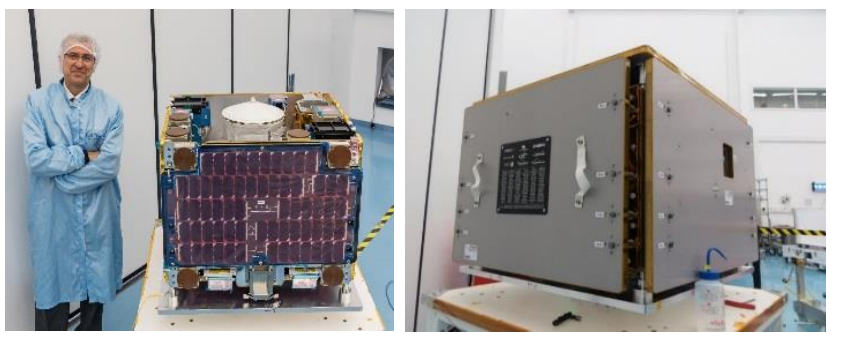

Figure 1: RemoveDEBRIS Satellite. Left: Satellite in the SSTL cleanroom, 14 December 2017. Right: Satellite with protective panels installed.
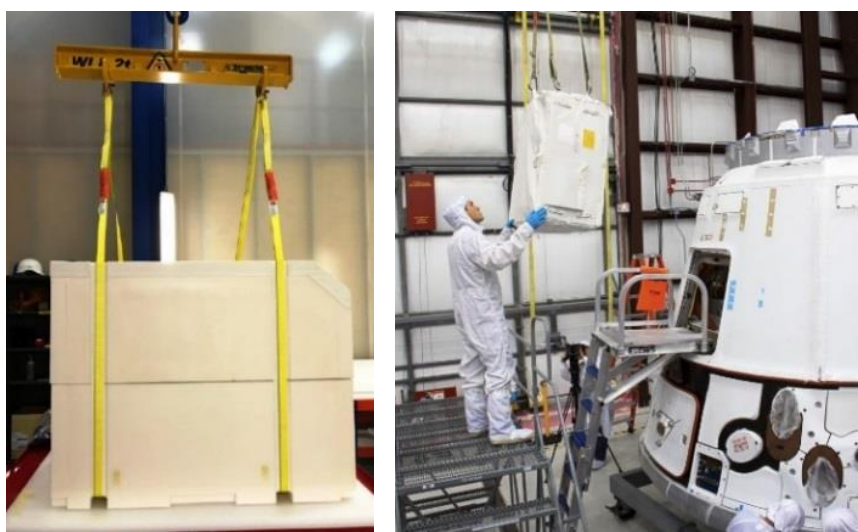

Figure 2 : Left: the clam shell (foam) that encompasses a RemoveDebris structural model, 2017. Right: loading of the Dragon capsule with a cargo bag. Credit: NASA, SpaceX from [44].

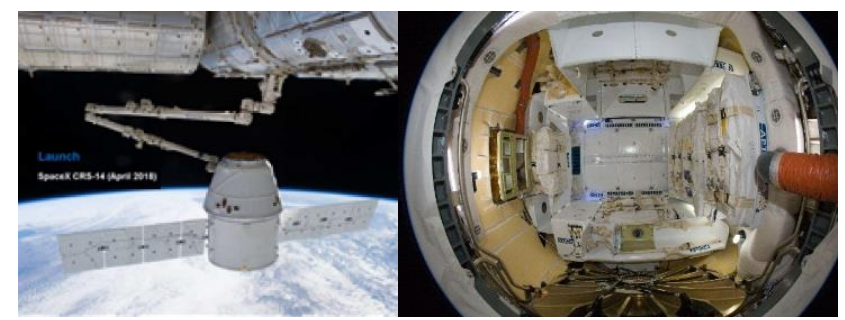

Figure 3 Dragon capsule. Left: view of the capsule approaching the ISS and captured by the ISS robotic arm. Right: View from the top hatch of the inside of the cargo bay of the Dragon capsule, showing CTB on the sides of the capsule. Credit: NASA, SpaceX

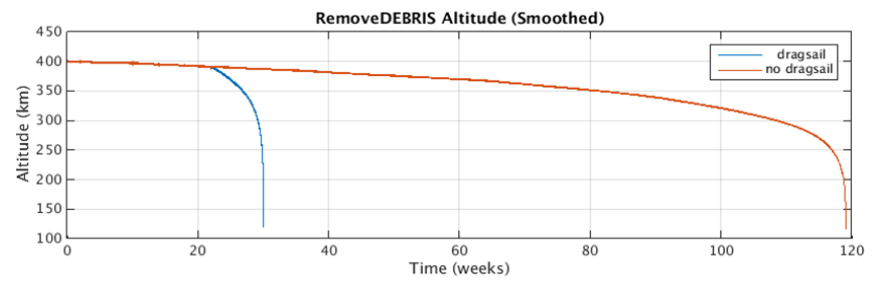

Figure 4: Predicted altitude of the RemoveDEBRIS satellite from release from the ISS to end of mission

\section{II.2. ISS operations}

After being taken out of the CTB, the craft, within its foam case was then transferred to the Japanese Experiment Module (JEM). Drew Feustel (ISS Commander) assisted by Ricky Arnold, performed the unpacking maintaining contact with the RomveDEBRIS team via video link. The craft with its protective panels, was extracted from the foam clamshell case (see Figure 5) and the protective panels removed. The craft was then installed on the sliding table (see Figure 6) of the JEM airlock, integrating it to the NanoRacks Kaber Microsat Deployer. Apart from handling tasks, no specific operation like battery charging, electrical checks, etc..., were requested to the astronauts. Once the table was slid into the airlock and the door closed, the airlock was depressurized. The space side door of the airlock was then opened, and the robotic arm with the Special Purpose Dexterous Manipulator (SPDM) grappled RemoveDEBRIS by the KABER interface.

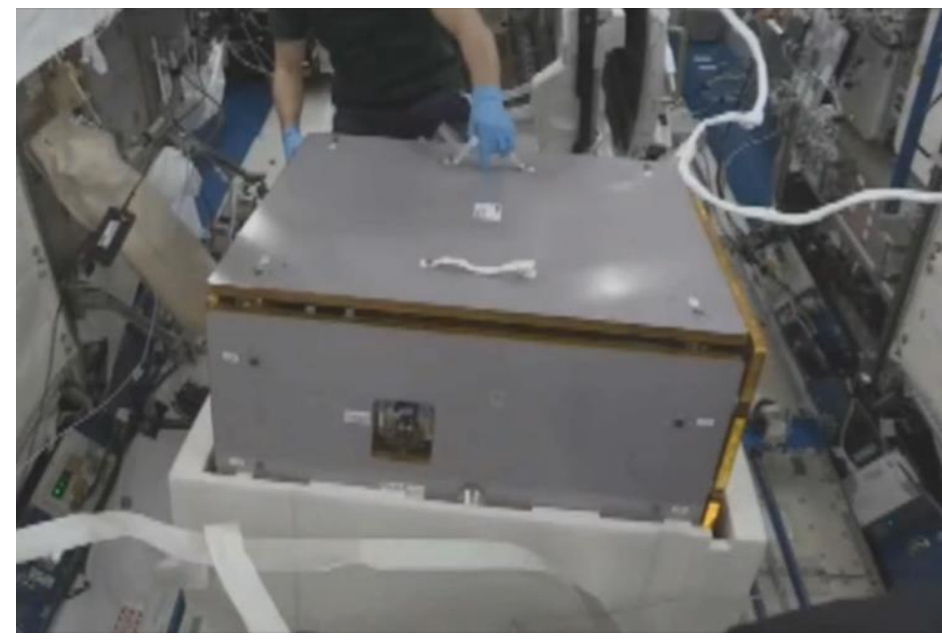

Figure 5: RmoveDEBRIS with its protective panels, is removed fomr the foam clamshell

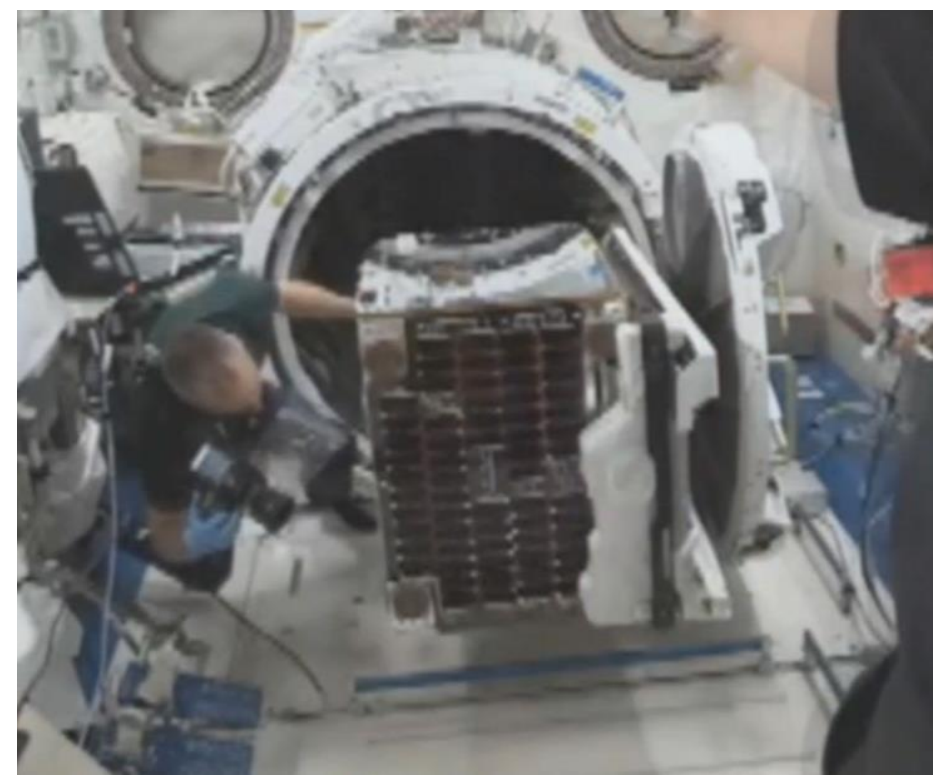

Figure 6: RmoveDEBRIS installed on the airlock sliding table 


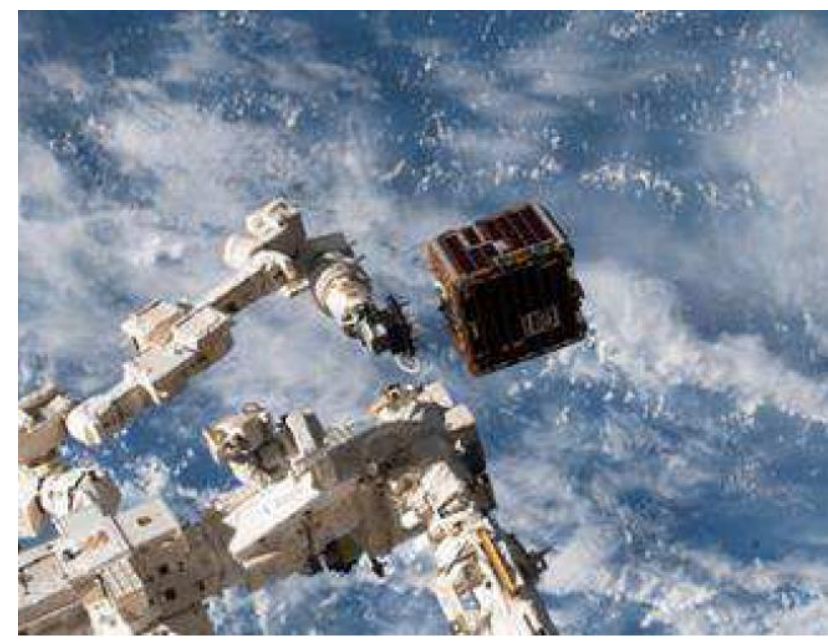

Figure 7: Release in orbit of RemoveDEBRIS

The craft is then moved by the robotic arm to a position and orientation from which it can be safely released in orbit (Figure 7), drifting away from the ISS. During all this period, all the platform subsystems remained turned off (Figure 8), as ISS safety imposed that the spacecraft needed to be fully off from 30 minutes minimum after deployment from ISS.

At the time of the RemoveDebris separation, the ISS was on a $\sim 405 \mathrm{~km}$ altitude orbit, and timers were triggered by 3 redundant mechanical switches implemented on the NRSS NanoRacks Satellite Separation system (PSC Mark II light band).

\section{II.3. LEOP and Satellite commissioning}

After $30 \mathrm{mn}$, timers activated the platform power subsystem, S-band receivers and survival heaters. The attitude of platform was free and not controlled.

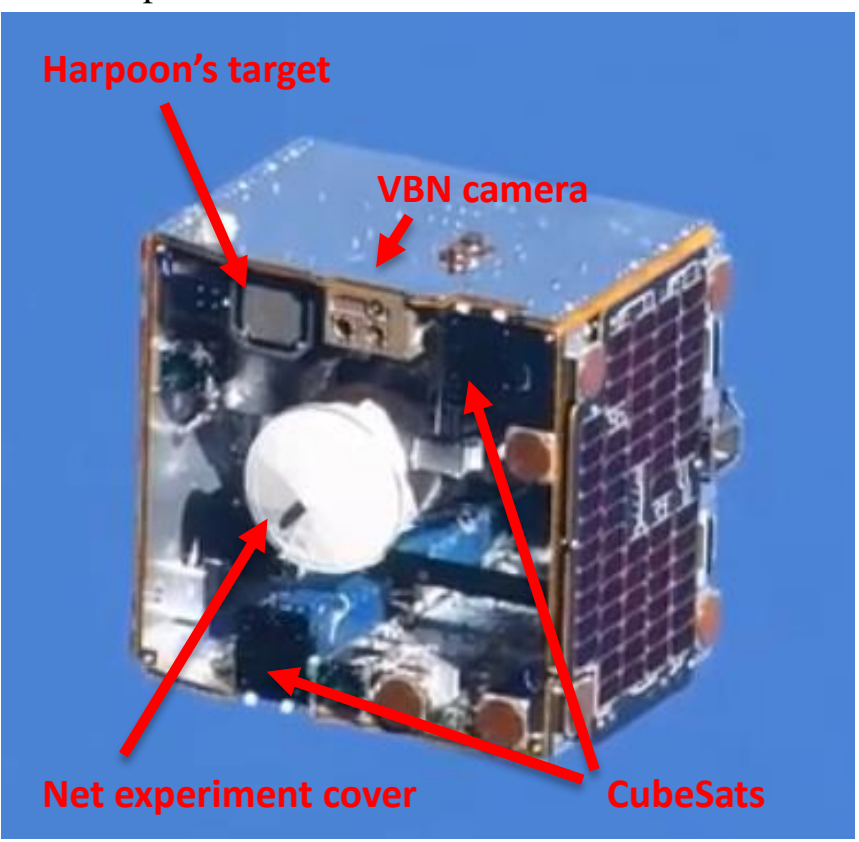

Figure 8: RemoveDEBRIS free flying, image taken by the ISS
During the first ground pass over the groundstation in Guildford, a command was sent by the ground segment to activate platform OBC and S-band transmitters. Preliminary communication and checkout tests were performed on the platform. Basic telemetry (e.g. battery charge) showed the craft was performing nominally and the attitude was acquired. This was followed by a slow de-tumbling of the spacecraft that was stabilized into a controlled safe attitude. AOCS commissioning then progressed until the platform was brought under control in a coarse Nadir pointing mode.

The platform commissioning continued checking all subsystem to ensure they survived launch and did not present malfunctions. For example, prime and redundant RF receivers, low rate transmitters and low level command links were checked.

The spacecraft then performed a series of AOCS manoeuvres to verify performance against that required for executing payload experiments.

During commissioning, an issue with the platform Gyros was detected, as the values measured were not consistent. The expected time for recovery was estimated at several weeks, even months.

Consequently, it was decided to develop an alternative mode for platform pointing without Gyro and named "nominal gyroless mode". This mode was successfully tested during commissioning and therefore provided the possibility to continue with the mission also without the Gyros.

The final phase was the payload commissioning, which included calibration and characterization. The Supervision cameras and VBN camera were tested over a range of exposures and frame rates (see Figure 9) which were planned for use for the experimental demonstrations

Overall, the commissioning phase lasted about 8 weeks, and this duration was consistent with the NASA request that no demonstrations should have been performed during a period of 2 month after separation to avoid risk of collisions with ISS. The timing of the various events is shown in Figure 10.
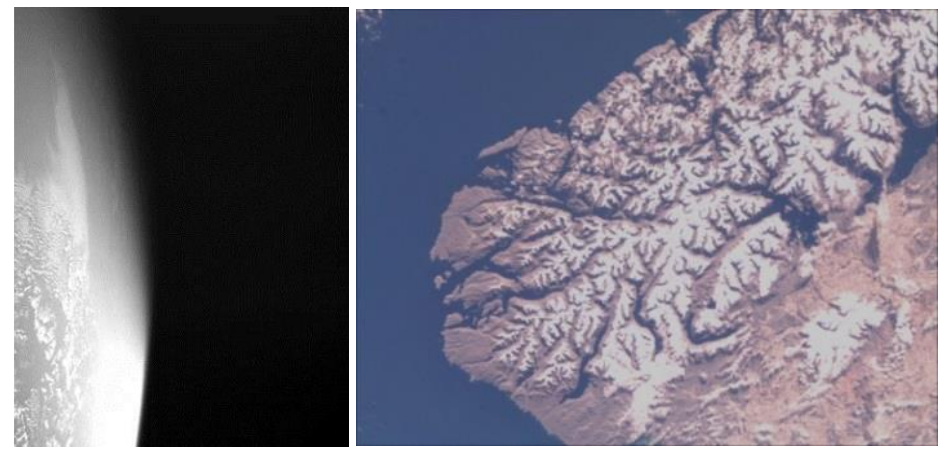

Figure 9: Examples of pictures used for the calibration of supervision camera and VBN. 


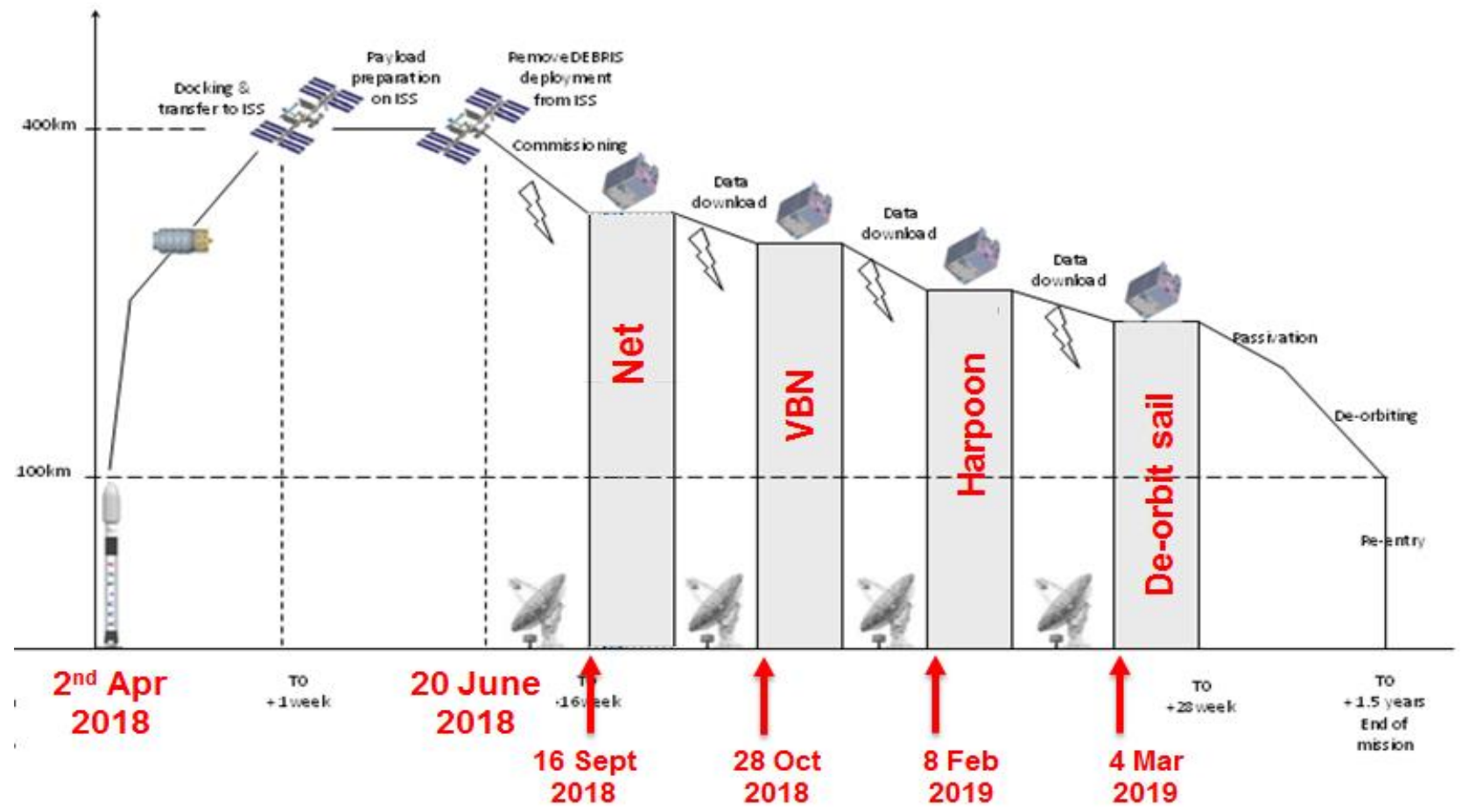

Figure 10: Launch Sequence. This figure shows the launch sequences for the mission to the International Space Station (ISS). Credit: SpaceX, NanoRacks, NASA [40].

\section{NET DEMONSTRATION}

The Net capture was the first demonstration to be carried out, and during this experiment the CubeSat DSAT\#1 was released at low speed from the ISIPOD\#1 installed on the mothercraft. DSAT\#1 then inflated a structure to increase its size thus becoming more representative of a large space debris, and was captured by the Net launched by the mothercraft. The specific details are reported in the following and in Table 2.

First, ISIPOD\#1 door was activated by the platform (T0) and DSAT\#1 slid out, restrained by the Cubesat Release System (CRS\#1)

Second, the CRS\#1 is activated by DSAT\#1 itself at T0+60s to eject DSAT\#1 using the energy stored in low stiffness leaf springs that pushed the cubesat gently away. The DSAT\#1 \& Net synchronization was done by timers starting the ISIPOD activation (T0). Magnetic sensors were used to confirm DSAT\#1 departure.

Platform pointing to Net deployment direction, platform compensation after DSAT\#1 departure and platform stabilization after Net deployment were performed nominally in the "gyro less nominal mode". All other sub systems (power, coms) behaved as expected. All OBC logs and TLM data was transmitted to ground.
Four different cameras supervised the experiment, Supervision camera $1 \& 2$ that captured 2305 images each (over a period of 440s), VBN 2D camera, that captured 17 images and finally the VBN 3D camera that captured 29 images.

Table 2: Net demonstration

\begin{tabular}{l|l} 
Parameter & Value \\
\hline $\begin{array}{l}\text { Solar angle for Net } \\
\text { opportunity }\end{array}$ & $|\beta|>40^{\circ}$ \\
\hline NETCAM mass & $6 \mathrm{~kg}$ \\
\hline Net size & $5 \mathrm{~m}$ diameter \\
\hline Platform Pointing & Open loop, stability $+/ 5$ \\
\hline Target: & $\begin{array}{l}\text { 2U Cubesat (DSAT\#1) Semi passive } \\
\text { with inflatable booms to become 1m } \\
\text { size }\end{array}$ \\
\hline $\begin{array}{l}\text { DSAT\#1 deployment } \\
\text { speed }\end{array}$ & V=5cm/s $+/ 20 \%$ \\
\hline $\begin{array}{l}\text { Target range for } \\
\text { capture }\end{array}$ & $7 \mathrm{~m}+/-1 \mathrm{~m}$ \\
$\begin{array}{l}\text { Complete } \\
\text { experiment duration }\end{array}$ & $440 \mathrm{~s}$ (DSAT\#1 at $\sim 300 \mathrm{~m}$ distance) \\
$\begin{array}{l}\text { Image capture: } \\
\text { Supervision cameras }\end{array}$ & B\&W, FOV=60, \\
\hline
\end{tabular}


After the release of DSAT\#1, a timer commanded the two cold gas generators to inflate the five booms of the assembly (design details in [3]).

There is video evidence of the inflation/deployment of two of the 4 lateral booms and the longitudinal boom, but the other two lateral booms do not appear to have deployed (See Figure 11). The deployed longitudinal boom can be seen in Figure 12, where it is also visible the triangular sail that would not have been deployed and visible unless the longitudinal boom had been deployed.
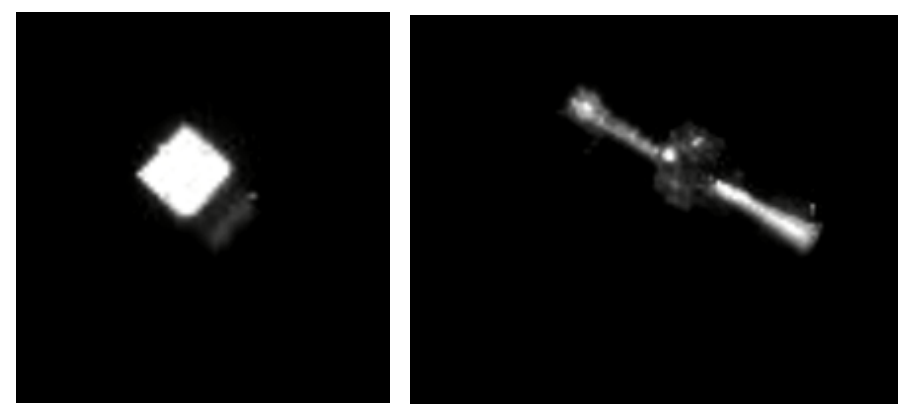

Figure 11: DSAT\#1 Left DSAT\#1 in stowed configuration drifting away from mothercraft. Right: DSAT\#1 with lateral inflatable booms deployed

Net deployment was performed 144s after DSAT\#1 departure $(\mathrm{T} 0+204 \mathrm{~s})$, theoretically leading to a capture at $7 \mathrm{~m}$ distance. However during the demonstration, DSAT\#1 velocity has been assessed based on the analyses of the timing of the images and known size of the objects and camera Filed of View. Results seems indicate that DSAT\#1 velocity was slightly higher than expected (about $50 \%$ higher than then planned $5 \mathrm{~cm} / \mathrm{s}$ at $7.5 \mathrm{~cm} / \mathrm{s}$ ).

The video stream shows that after deployment of its inflatable booms, DSAT\#1 started spinning which is consistent with a gas leak from the lateral booms which did not inflate/deploy correctly. It is likely that this has been the result of the lateral door of the boom compartment not opening, which would have prevented the boom from expanding under the pressure of the inflation. Constraining the boom would have generated a further increase of pressure that is likely to have contributed to a rupture of the boom producing a small air jet that acting like a thruster, would have imparted an angular speed to the CubeSat.

This might have also contributed to the lateral drift of the cubesat, as it was moving away from the mothercraft.

Figure 12 show the net opening up as it travels toward DSAT\#1, pulled by the 6 masses at its vertexes, which travelled along diverging trajectories, so that the net unfolds in the shape of a six point "star" where each of the vertexes is pulled by one of the masses.
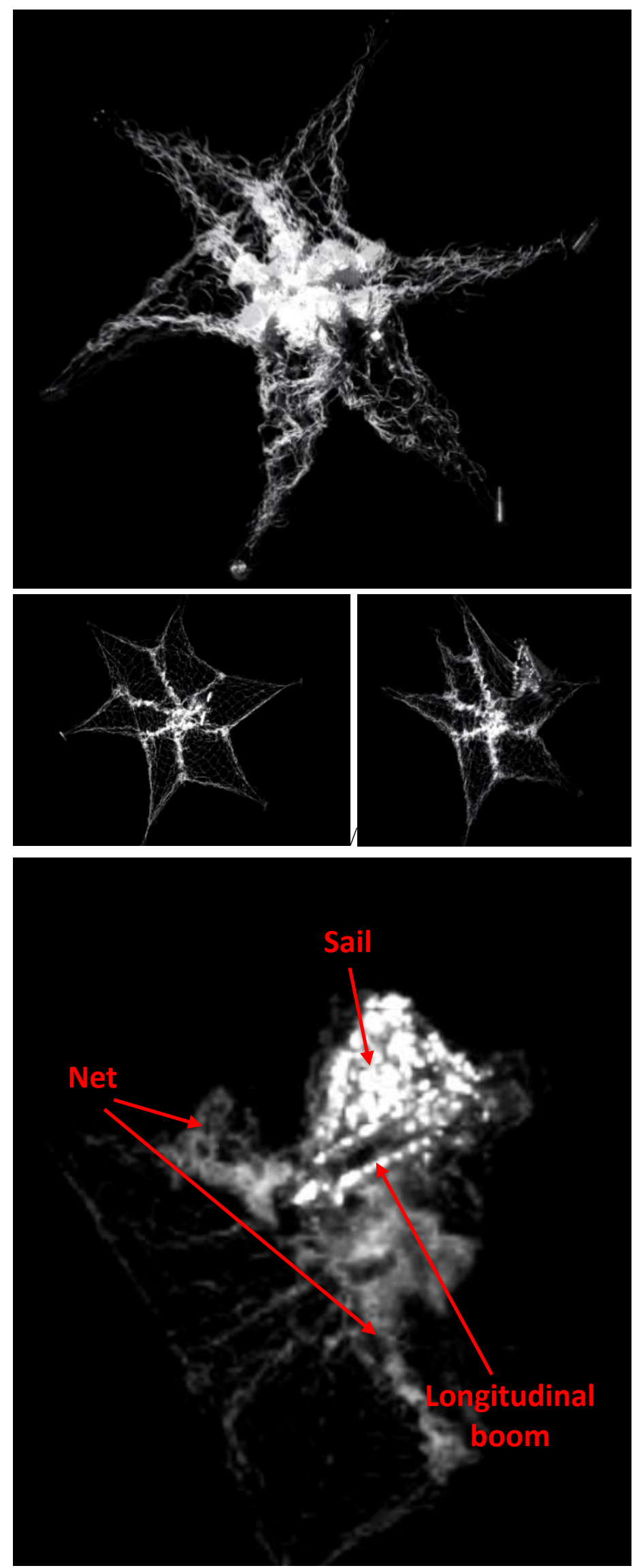

Figure 12: Launch of the net towards DSAT\#1 Top: Net opening pulled by the 6 throw masses, Muddle: the net continues to stretch and beyond it DSAT\#1 is visble, Bottom: moment of the capture, DSAT\#1 entangled in the net. 
The moment of the net contact with the target, is visible in the last photogram of Figure 12 where DSAT\#1 is captured by the edge of the net. The net then completely envelops DSAT\#1, wrapping itself around the spinning object and drifting away with it.

Analysis of the images, with knowledge of the width of the Field of View, shows that that the DSAT\#1 capture occurred at approximately $11 \mathrm{~m}$ from the mothercraft, and the net stretched to a maximum of $4 \mathrm{~m}$ diameter vs the $5 \mathrm{~m}$ that is the actual diameter of the net when completely stretched open.

The 6 throw masses that pulled the net open were equipped with internal mini winches to draw a string that was running around the perimeter of the net, in order to close it after the capture of DSAT\#1. The mini winches were driven by electric motors supplied by super-capacitors, acting like batteries, and were activated by a timer to start closing the net after the contact with the target.

There are no indications from the videos taken by the supervision cameras that the active closure of the Net was not performed, however, due to the enlarged capture distance $(\approx 11.5 \mathrm{~m}$, whilst the design was optimized for 6 $\mathrm{m})$ it was not possible to get a positive indication from the images either.

This demonstration was also used to verify the correct functioning calibration of the LiDAR cameras, and related procedures, before the VBN demonstration.

The end of the demonstration was planned after 440s (with DSAT\#1 at $\sim 300 \mathrm{~m}$ distance) and $\sim 2$ weeks were allocated for data downloading.

Final decay of DSAT\#1 enveloped in the net was predicted for the 4th March 2019, and independent data (two line elements of the object), showed that the object re-entered and burned into the atmosphere on the $2^{\text {nd }}$ of March 2019.

\section{VBN DEMONSTRATION}

This experiment had two major objectives:

- Demonstrate state-of-the-art of Image Processing (IP) techniques and navigation algorithms based on actual flight data (raise TRL to 5), acquired through two sensors: a standard camera and a flash imaging LiDAR (developed by CSEM)

- Validate a flash imaging LiDAR in flight, raising its TRL from 2 to 7.

The deployment direction of the target (DSAT\#2) for this experiment was driven by two criteria: i) the risk of collision between platform and DSAT\#2 after deployment must be minimized, ii) DSAT\#2 must enable the acquisition of images with range from [0;1000m], various backgrounds (Earth and black sky), and lighting conditions (daylight and eclipse).

The plan was to observe DSAT\#2 drifting away at a speed of $2 \mathrm{~cm} / \mathrm{sec}$ using the VBN: 2D Camera (FoV 18deg ) and the 3D Flash LiDAR (FoV<10deg).

The end of the demonstration was planned for $4 \mathrm{~h} 30(\sim 3$ orbits) after the deployment of DSAT\#2, which by then was supposed to be at $750 \mathrm{~m}$ from the mothercraft.

Also the supervision camera SV0 on the mothercraft observed the DSAT\#2 drifting away.

SV0 took in total 3691 images over 4h02mn50s: (1947 images during its $1^{\text {st }}$ orbit, 1161 during the 2 nd orbit and 583 during the 3 rd orbit ), the 2D and 3D VBN cameras took a total of 361 images each.

For the LiDAR camera, the angle of the surfaces that are observed is crucial to determine their performance, as this governs the ratio between the diffused-reflected sun light and the laser light reflected by the target that hit the camera detector. The best case for the LiDAR (and the worst for the cameras) is when specular light from laser and no, or only diffused light from sun are collected.

During the experiments, the angle with the sun light was to favor the cameras. Hence, images were captured in the less favorable situation for the LiDAR, with specular sunlight reflection into detector.

This is illustrated by the pictures in Figure 13, taken at a few seconds interval by the VBN color camera (left) and by the VBN LiDAR (right).
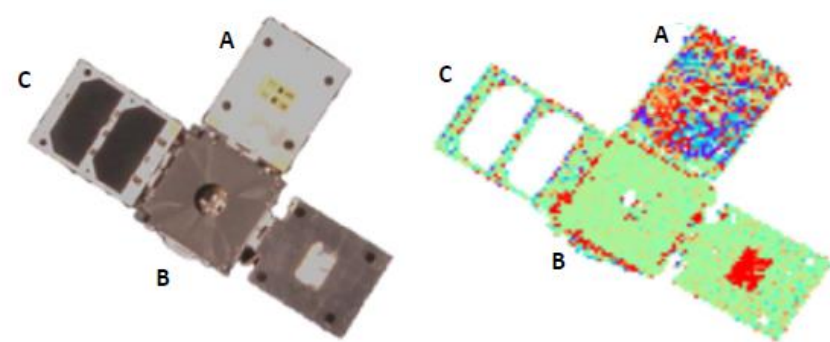

Figure 13: Left, VBN color camera Right LIDAR images taken at 4 seconds interval during VBN experiment

Each color on the LiDAR image represents a distance. On the panel A of the DSAT\#2, the sunlight reflected into the LiDAR detector is such that the distance measurement is noisy (many different colors on close neighbor pixels). On the panel $\mathrm{B}$, which is protected against specular sunlight reflection by panel $\mathrm{C}$, the colors are much more uniform.

The field of view (FOV) of the LiDAR and camera are respectively of $8^{\circ} \times 6^{\circ}$ and $21^{\circ} \times 16^{\circ}$. This design choice resulted from the tradeoff of counter requirements for a large field to increase the chance of viewing the target despite the uncertainty on its relative trajectory uncertainty and for sufficient spatial resolution to resolve a target of $20 \mathrm{~cm}$ as far as possible (see Figure 14). 

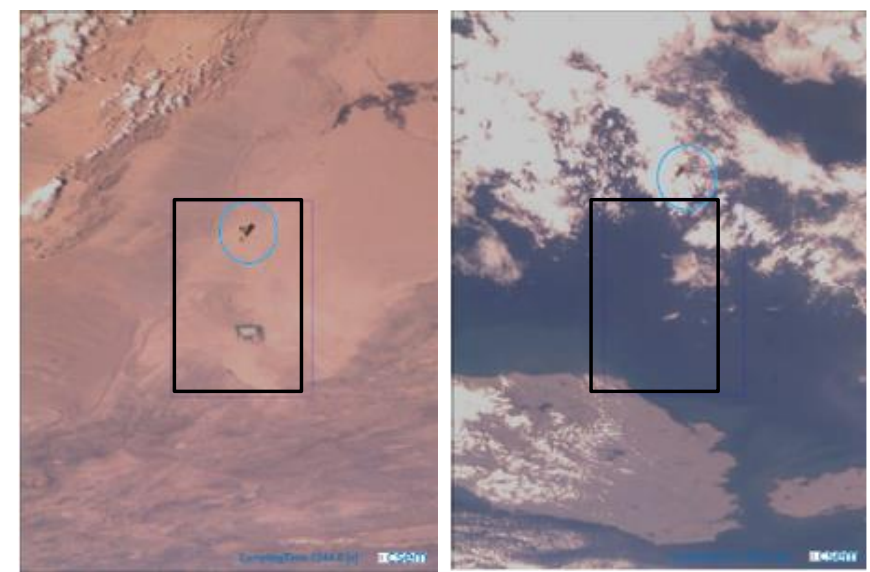

Figure 14: Left DSAT\#2 in the FoV of both standard camera and LIDAR, right DSAT\#2 still in the FoV of standard camera, but out of the LIDAR FoV.

The ground truth available for the VBN experiment is provided by the GPS integrated in the DSAT\#2. With the GPS positions transmitted via the wireless Inter Satellite Link between the target (DSAT\#2) and the chaser (mothercraft), we have the possibility to know roughly the relative distance between the two satellites. In Figure 15, some of the distances measurement by the LiDAR have been superimposed on the plot of the distances generated from the GPS data, showing a good match between the two sets of measurements

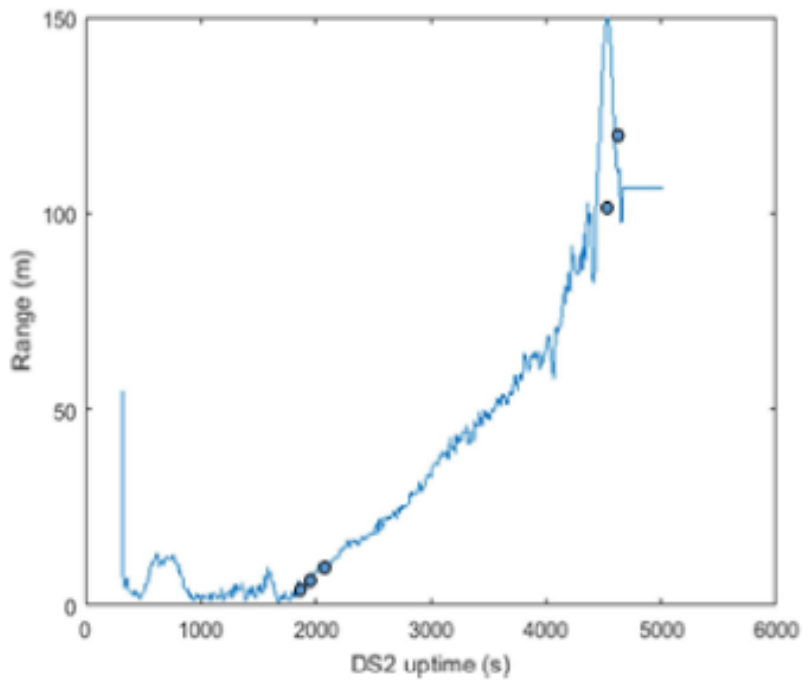

Figure 15: Comparison of distance as measured from GPS (continuous line) and LIDAR discrete circles.

From Figure 15 it is possible to notice that there is no valid LiDAR measurement between 2100 and 4500 [s]. During this period of time Earth was in the background and distance measurement cannot be derived from the raw LiDAR images. This is illustrated in Figure 16, where the target signal is completely buried in the background noise.

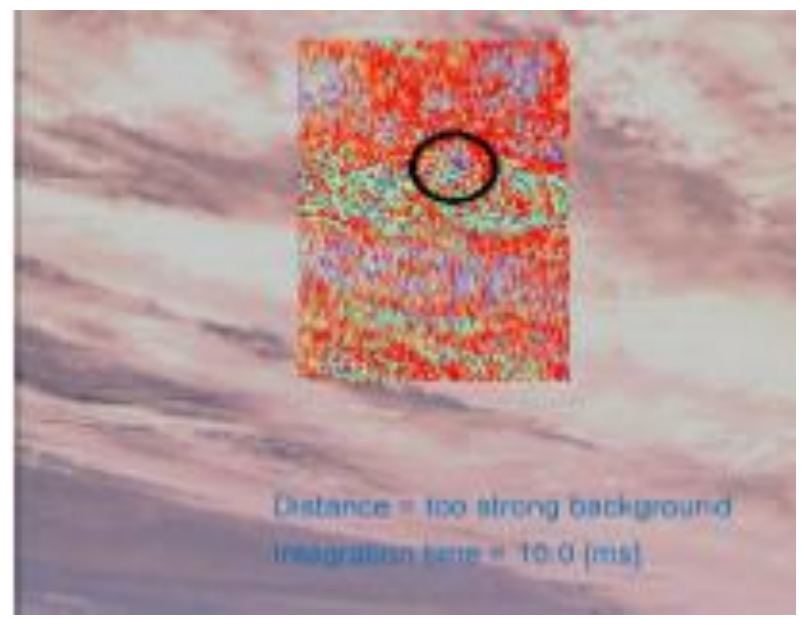

Figure 16: Superposition of color camera and LiDAR images with earth in the background

The first fact to be highlighted, and shown in Figure 18, is that DSAT\#2 remained in the cameras field of view over the entire sequence, meaning that the attitude guidance profile was correctly generated and followed by RemoveDEBRIS, and that dispersions at ejection remained at an acceptable level

Different VBN algorithms provide 3DoF (position only) and $6 \mathrm{DoF}$ (position and attitude) relative navigation depending on the rendezvous phase. At far and medium range, only $3 \mathrm{DoF}$ (position only) relative navigation is needed and performed. At short range, $6 \mathrm{DoF}$ (position and attitude) relative navigation is required for successful capture.

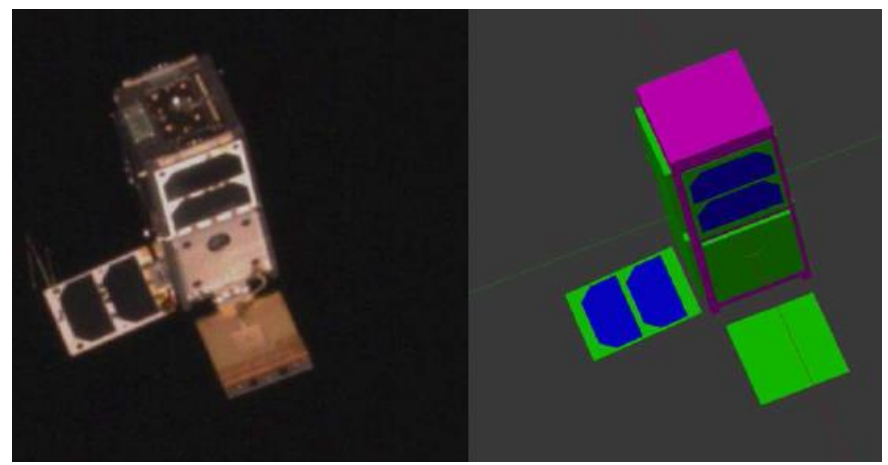

Figure 17: DSAT\#1 Left: As seen by the camera, Right CAD model

The Airbus in house developed tracking algorithm has been tested on the VBN camera images. This solution had to be improved in order to deal with the low acquisition frequency of the VBN camera $(0.1 \mathrm{~Hz})$, showing good results as long as the background is dark. This is illustrated by the green contours illustrate the 3D model of the target which has been matched by the algorithm to the actual DSAT\#2 image. 


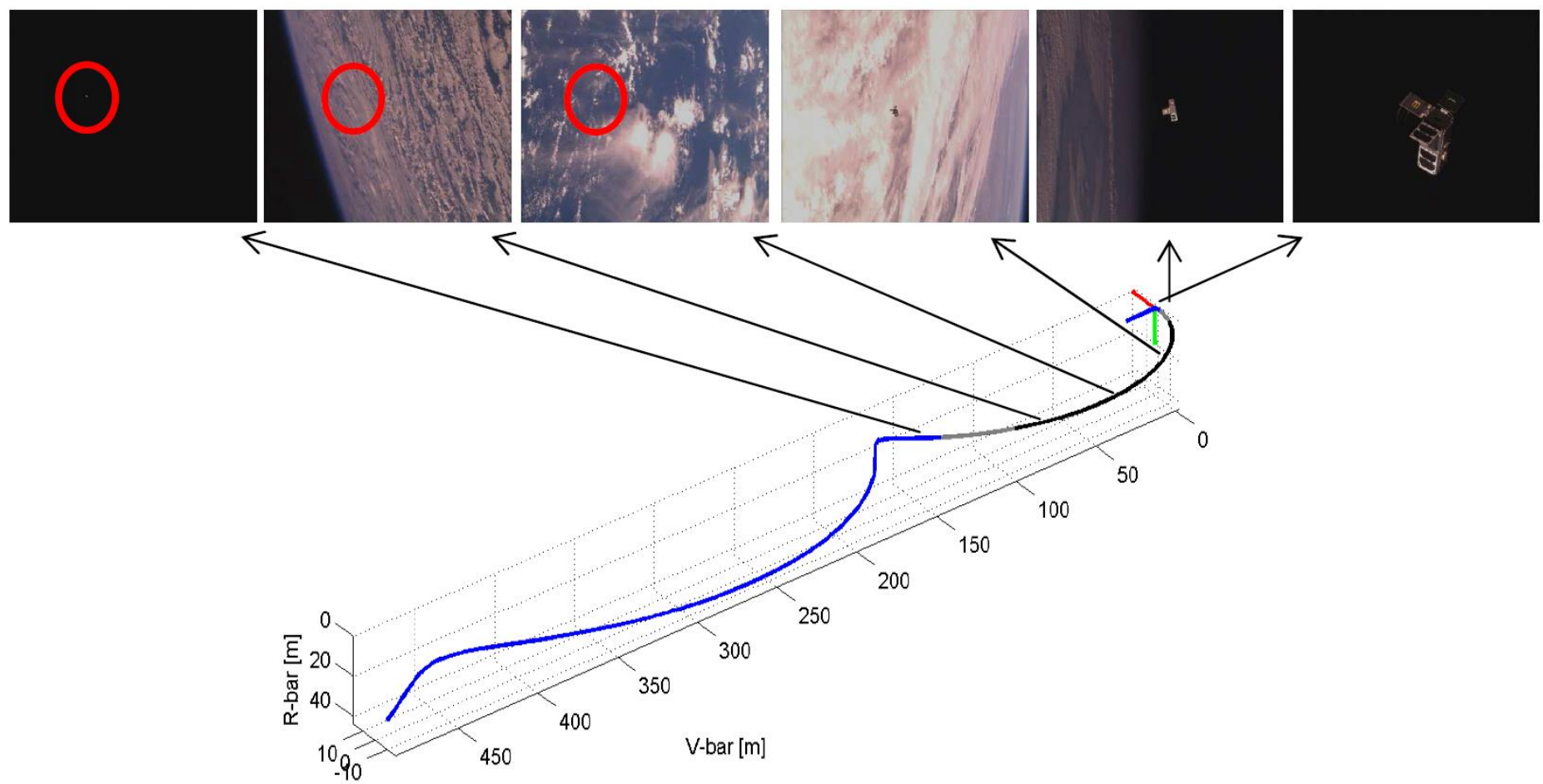

Figure 18: DSAT2 within VBN camera field of view over the reference trajectory

However, when Earth is in background, performances are degraded due to several factors, e.g. Saturation, Low size of target in FoV and JPG artefacts.

An a priori knowledge of a 3D model of the target (see Figure 17) is matched to an image in an iterative fashion, leading to an estimate of the relative position and attitude between the camera and the target.

The proposed approach relies on a frame to frame Model based tracking in order to obtain the complete pose of the CubeSat (position and attitude) with respect to the vision sensor. It minimizes the error between visual measurements in the image and the projection of the 3D model of the CubeSat. Tracking and pose estimation are thus simultaneous. It can also be combined with an extended Kalman Filter to improve the navigation precision.

Images (1280x1024 pixels, $12 \mathrm{~mm}$ lens) were acquired at $3 \mathrm{~Hz}$ with successively 3 different aperture times, meaning that successive images at same aperture were acquired at $1 \mathrm{~Hz}$. In particular, the CubeSat (DSAT\#2) has been successively tracked and localized (see Figure 20 ). Note that the processing time for each frame is less than $0.1 \mathrm{sec}$.
The results from the image processing algorithms based on Supervision camera images and VBN camera images are shown hereafter in Figure 19, together with LiDAR data, GPS measurements and the expected, nominal DSAT2 trajectory. Based on the processing of the data, the following statements may be made: SV0 and VBN camera measurements are consistent $(2.3 \mathrm{~cm} / \mathrm{s}$ ejection), LiDAR measurements are close to expected trajectory (2 $\mathrm{cm} / \mathrm{s}$ ejection), GPS measurements do not seem reliable for short range $(<10 \mathrm{~m})$.

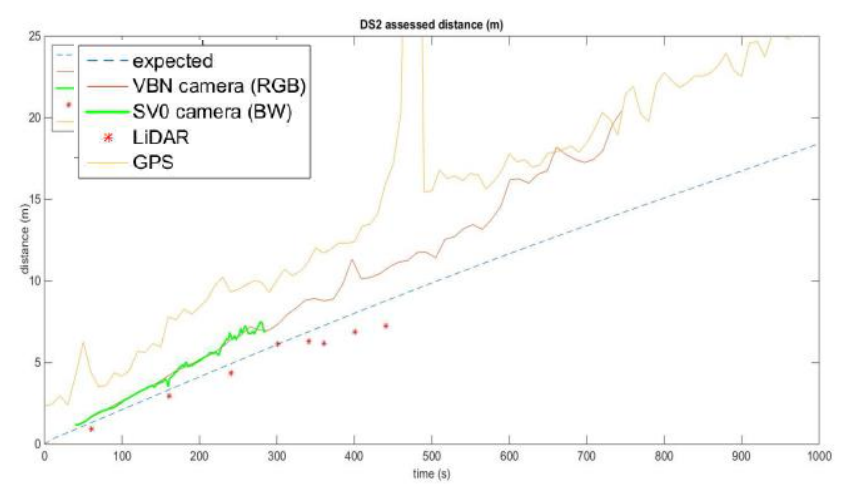

Figure 19: Comparison of different relative distance estimations between DSTA\#2 and RemoveDEBRIS mothercraft. 

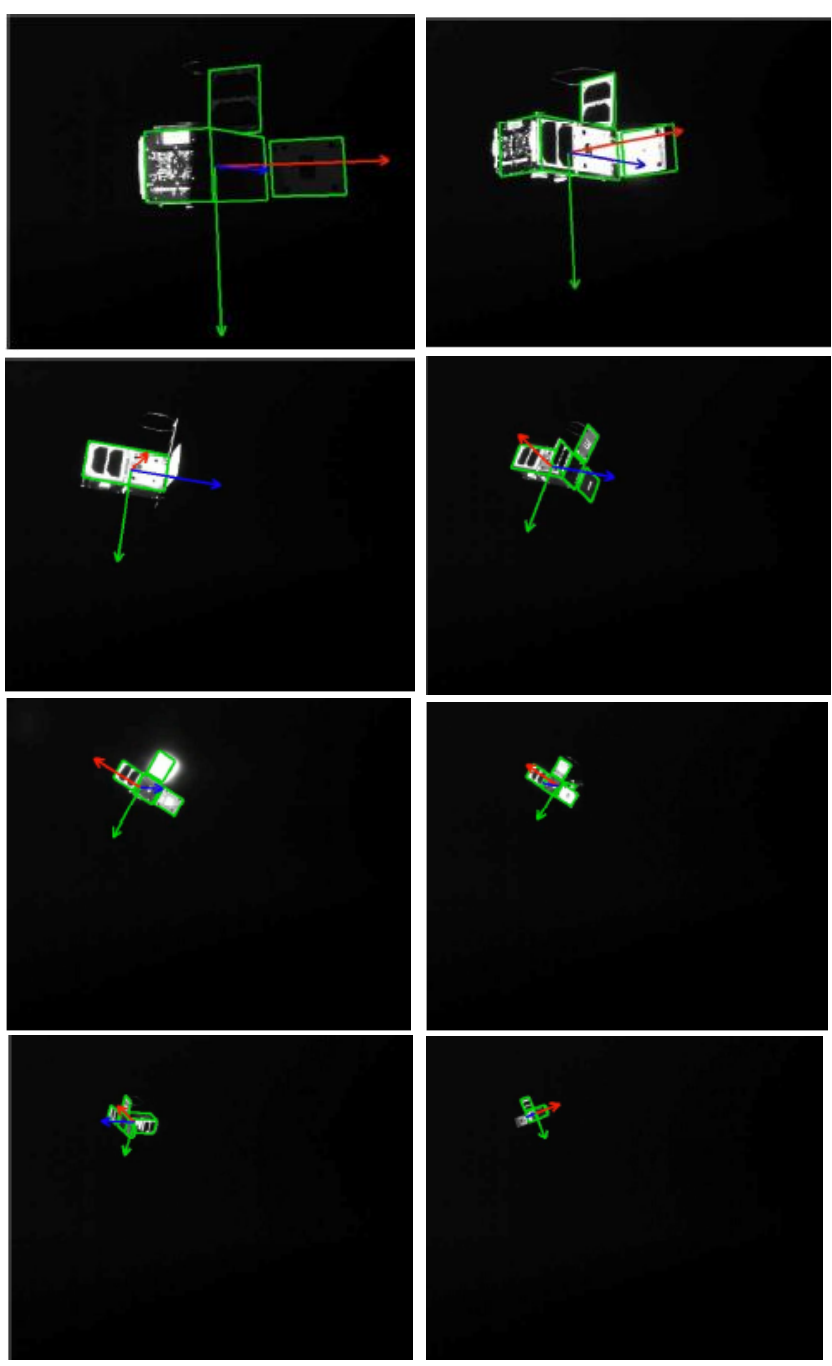

Figure 20: VBN images of DSAT\#2 for the removedebris sequence (Inria Algorithm). The cubesat has been successively tracked and localized on 210 successive images (that is, during $210 \mathrm{~s}$ ))

Further analysis has been performed in order to process the GPS data provided by the DSAT2 and mothercraft, with the objective of achieving a reference relative trajectory, to be used as a ground truth against which the VBN performances could be assessed, however these results show some irregularities and more in-depth analysis will be required.

\section{HARPOON DEMONSTRATION}

This was the third demonstration planned, articulated in two mains steps: the deployment of the fixed target performed on January $26^{\text {th }} 2019$, and harpoon firing performed on February $8^{\text {th }} 2019$.

The Harpoon capture demonstration included three Go/NoGo reviews: 1st to confirm the opportunity window before pretesting platform, 2nd to confirm the correct platform status and allow target deployment, and 3rd to confirm the correct deployment and stability of the target to collegially agree for a Go for harpoon firing.

The main phases of the demonstration were: i) Predemonstration tests (cameras testing), ii) software uploading for HTA target deployment, iii) platform pointing (Earth pointing, as it was requested an alignment with Earth background to better see the harpoon and tether during firing), iv) software uploading for target deployment, v) target deployment, vi) images acquisition to verify correct target deployment, vii Software upload for actual demonstration, viii) harpoon firing.

The decision to fire the harpoon against a fixed target, rather than a free flying one, reduced the unnecessary complexity as only the firing mechanism and harpoon flight/impact needed to be tested. In turn this also increased the payload safety. The dimensions of the elements is reported in Table, and the material (Aluminum honeycomb) was selected specifically to be representative of the composite structures used on large satellites that are potential targets for removal.

Two supervision cameras with different parameters were set to record the experiment:100fps / Narrow FOV (40\%), $40 \mathrm{fps} /$ Large FOV (100\%).

After the demonstration, the retraction of the boom would have been considered as this could have interfered with SBand HR communication. Two weeks were initially allocated for data downloading.

\section{Table 2: Harpoon experiment data}

\begin{tabular}{l|l}
$\begin{array}{l}\text { Parameter } \\
\text { Harpoon Target } \\
\text { Assembly }\end{array}$ & Value \\
\hline Harpoon (projectile) & mass $0.115 \mathrm{~kg}$ \\
\hline $\begin{array}{l}\text { Target size \& } \\
\text { material }\end{array}$ & $\begin{array}{l}\text { approx. } 10 \mathrm{by} 10 \mathrm{~cm} \text {, Aluminium } \\
\text { Honeycomb panel }\end{array}$ \\
\hline Target & $\begin{array}{l}\text { fixed at the end of } 1.5 \mathrm{~m}(+/-10 \%) \\
\text { deployable boom }\end{array}$ \\
\hline Harpoon velocity & Nominal $20 \mathrm{~m} / \mathrm{s}$ \\
\hline $\begin{array}{l}\text { Planned image } \\
\text { capture }\end{array}$ & $\begin{array}{l}51 \mathrm{~s} \text { with supV0 (100fps), } \\
71 \mathrm{~s} \text { with SupV1 (40fps) and } \\
5820 \mathrm{~s} \text { with VBN (2D\&3D) }\end{array}$ \\
\hline
\end{tabular}

As planned, after the target had been deployed, images were downloaded to the ground station to check the correct positioning and stability of the target. The images showed that during the boom deployment, there was an increasing rotational oscillation of the target (see Figure 21 and Figure 22). This was initially attributed to the the vibration produced by the motor uncoiling the boom, and the low rotational stiffness of the boom; however, even after the deployment was completed, the oscillations continued. Subsequent imagery still showed significant oscillations of the target (up to +/-10 degrees), as shown 
in Figure 21. The cause of the oscillation was deemed to be the action of the AOCS of the satellite, amplified by the low resonance frequency (and low damping) of twisting mode of the boom-target assembly

The mid position of the target was consistent with the images taken during alignment tests on the ground, and a more detailed analysis of the movement showed that even at the maximum of the amplitude of the oscillation a portion of the target was in the line of sight of the harpoon. Therefore provided that the harpoon hit the target within a $10 \mathrm{~mm}$ radius from its line of sight, the experiment could have been performed.
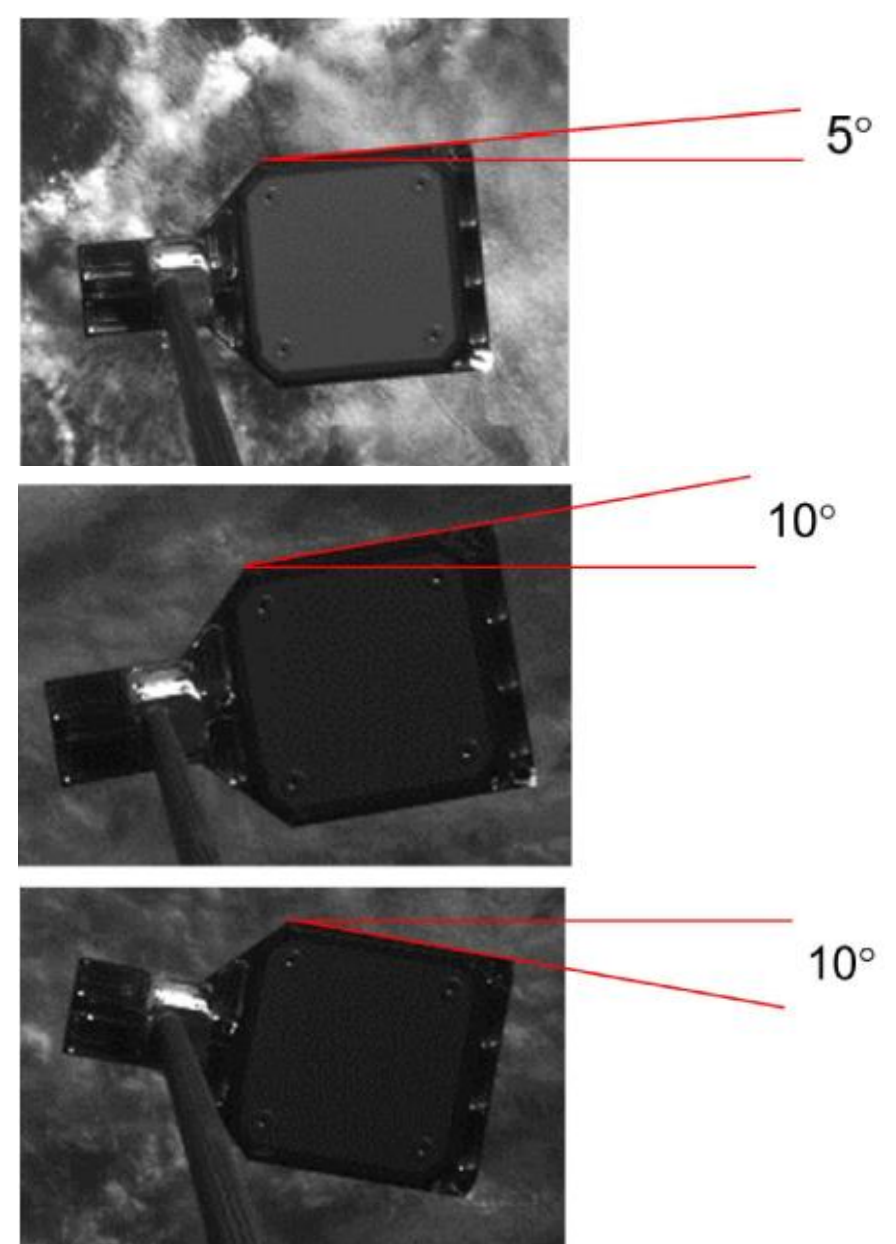

Figure 21: rotational oscillations of the target a) during boom deployment, b) and c) steady state oscillations with the boom completely deployed

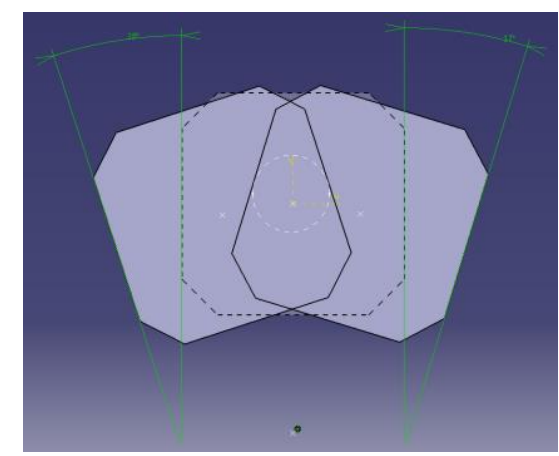

Figure 22: CAD reconstruction of maximum target movement
However, it was decided to attempt to stabilize the target reducing the mechanical inputs produced by the AOCS. This was reconfigured in order to reduce the actions of the platform actuators to the minimum. After a period to allow the natural damping of the system to reduce the oscillations, the target appeared stable with only very minor movements $(<0.5 \mathrm{deg})$ and therefore it was possible to proceed with the demonstration with minimum risk.

Onboard the harpoon deployment chamber were two cold gas generators' (CGG) heaters, these were thermostatically controlled and kept the CGGs at working temperature (between $10^{\circ} \mathrm{C} 40^{\circ} \mathrm{C}$ ).

A preprogrammed command sequence was uploaded to open the harpoon door and fire the projectile. The harpoon was fired as planned and successfully captured the target, achieving a firing speed of $19 \mathrm{~m} / \mathrm{s}$.
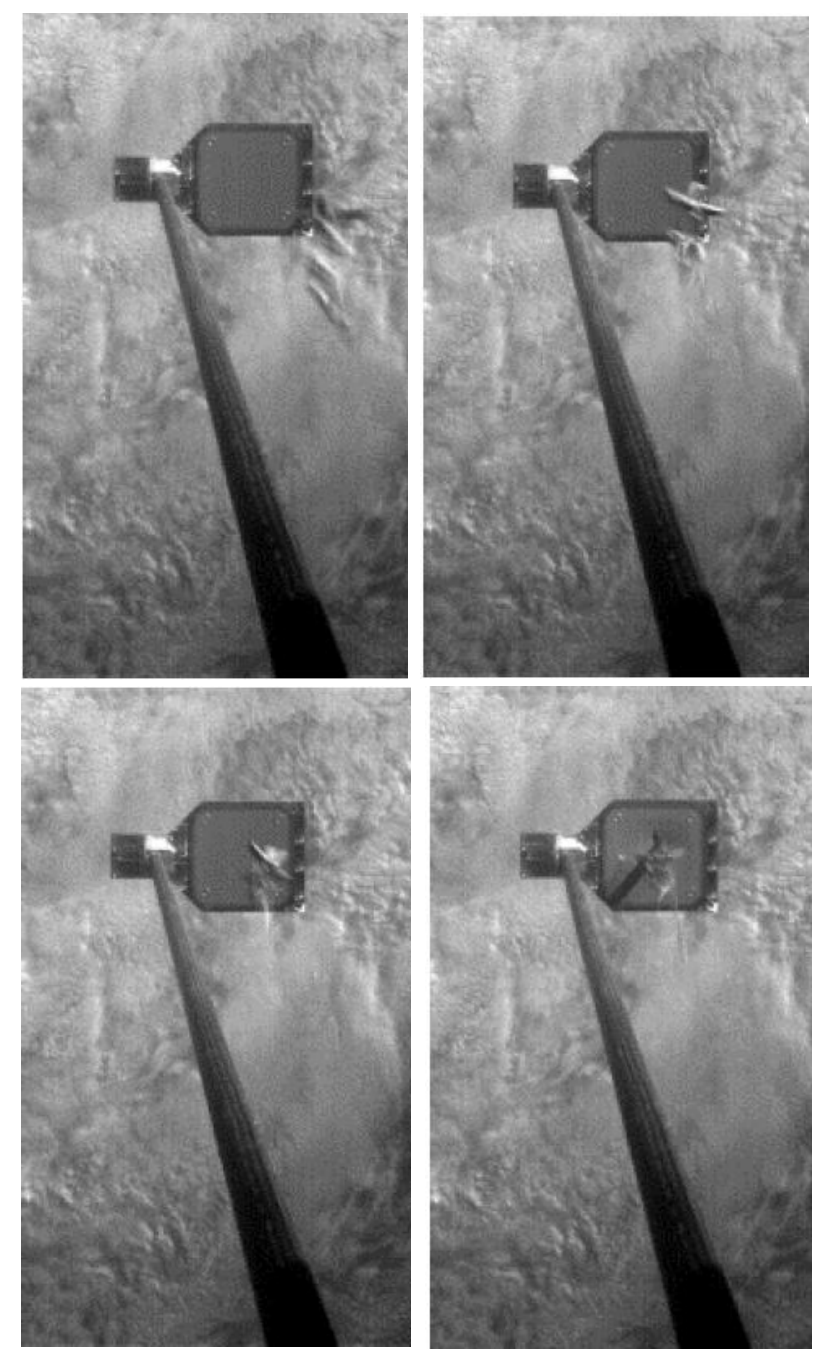

Figure 23: Harpoon impacting the target.

Onboard camera footage recorded the firing performance, with the projectile attitude, accuracy and speed all shown to be consistent with the performance data acquired on ground. A snapshot of the firing sequence can be seen in 
Figure 23, and Figure 24 shows that the harpoon has actually hit the target as expected, in the centre.

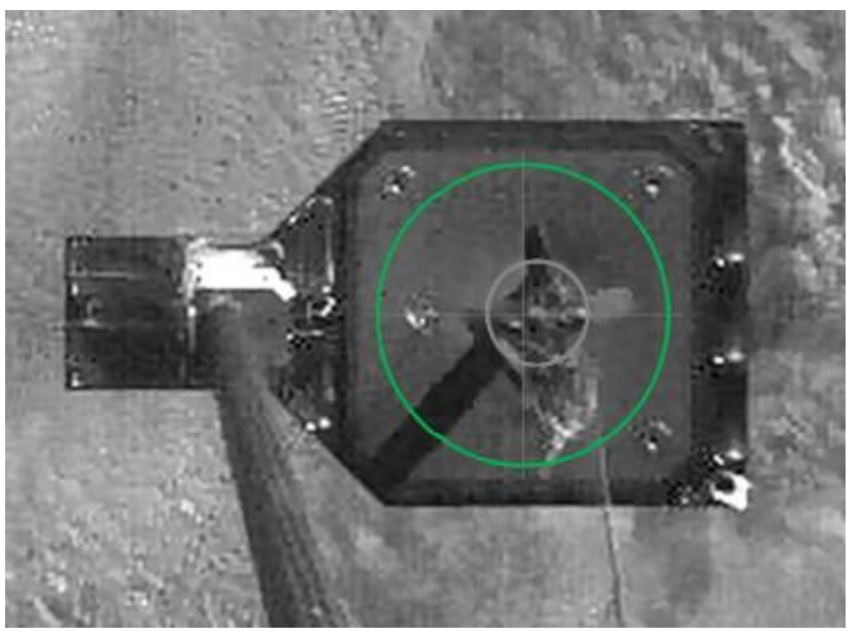

Figure 24: Harpoon imbedded in the target

During tests on the ground it appeared that the mechanical shock produced when the harpoon hit the target (mainly due to the high velocity of the harpoon) was so high that it snapped the target off of the tip of the boom. To address this issue a Delrin clock spring between the tip of the boom and the target was considered, in order to reduce the peak stress on the materials upon impact. This device was successfully ground tested as shown in Figure 25. However as the harpoon is imbedded in the target and tethered to the mothercraft, the separation of the target (braking off from its supporting structure) does not pose particular risks. In addition the spring element added complexity and flexibility to the assembly and therefore it was decided to proceed with a flight model that did not include such a feature.
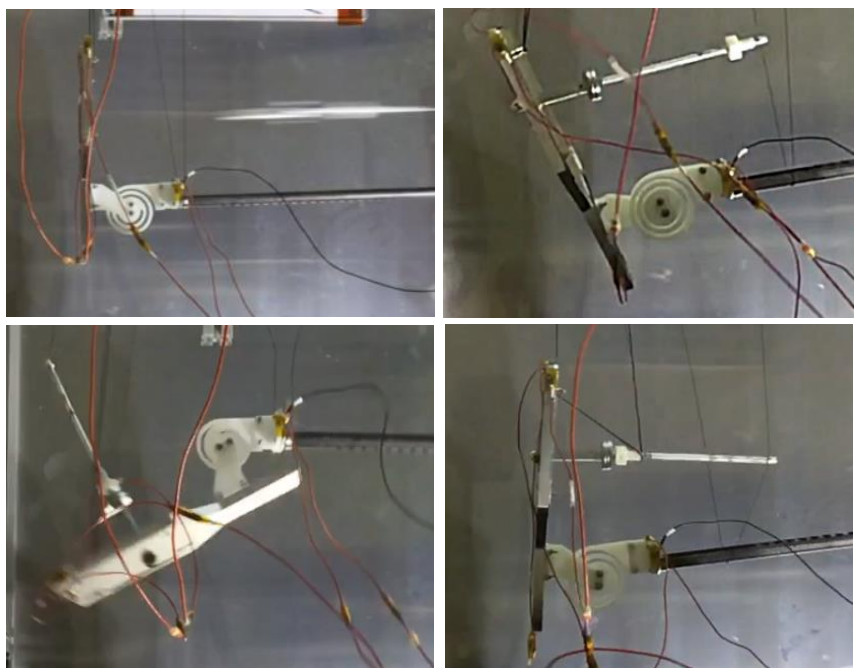

Figure 25: Spring/shock absorber, sequence showing the target being hit by the harpoon, rotating thus reducing the shock on the boom and finally returning to its original position
When the harpoon hit the target, the end of the deployable boom snapped, and the target coming off is visible in Figure 26, where it is also possible to see that the harpoon is tethered and therefore the target has been safely captured.

Eventually, after floating for a while in space tethered to the mothercraft, the target and harpoon ended up wrapped around the boom as visible in Figure 27

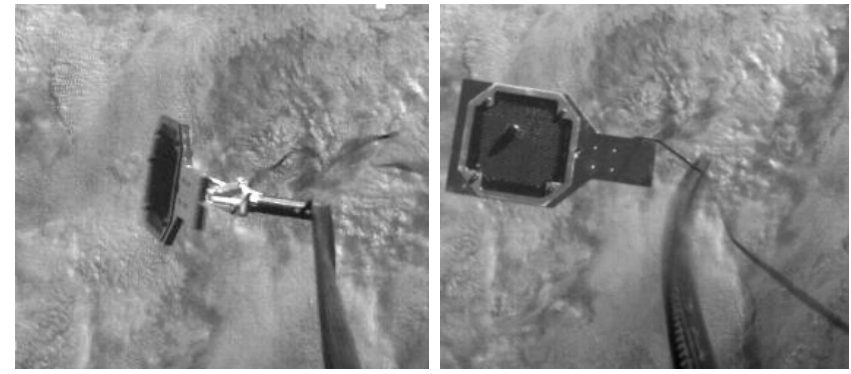

Figure 26: Boom snapping off and target coming off, tethered to the mothercraft

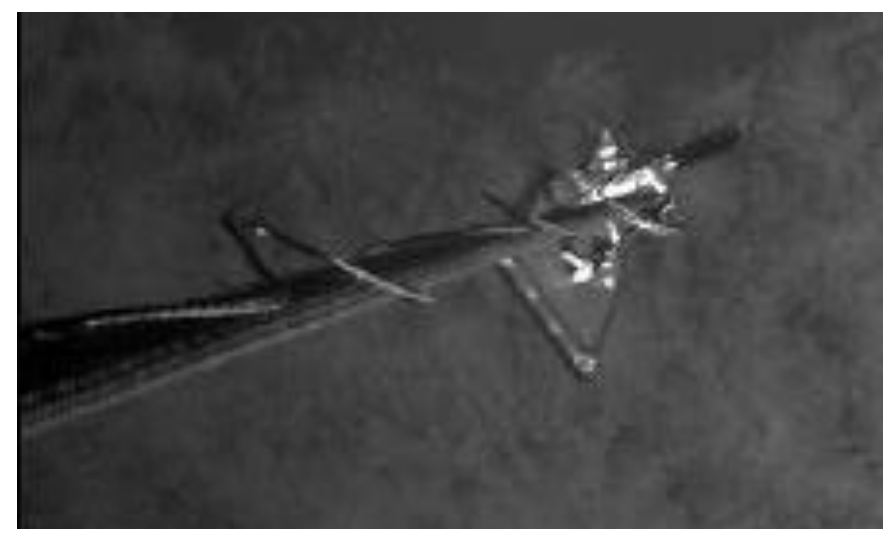

Figure 27: Target and its tether wrapped around the boom.

\section{DRAGSAIL}

Like for any active debris removal mission, the last phase of the mission would be to dispose of the debris, in this case the fourth and final demonstration was the dragsail. This is a drag augmentation device that, thanks to the residual atmosphere in low earth orbit, slows down the spacecraft, progressively reducing the altitude of its orbit until the craft burns in the high atmosphere.

In order to avoid interference with the other payloads, and in particular with the deployable boom of the HTA, (as a malfunction might have left the boom deployed thus preventing the full deployment of the dragsail) the dragsail was mounted on the other side of the spacecraft. The decision to mount the dragsail so that its deployment was in the opposite direction to all the other payloads meant that none of the cameras could actually observe the deployment of the device. Therefore the successful deployment of the dragsail had to be indirectly confirmed 
by other means, namely, i) examination of the power profile provided to the dragsail during activation, ii) reduction in power generated by the solar panels due to shadowing of the sails, changes in telemetry from the sun sensor, iii) changes in the two-line element set (change in the slope of the altitude versus time curve), iv) observation from the ground (significant changes in brightness).

The command to deploy the dragsail was issued on the 4th March 2019. The first telemetry available was the power profile from the craft, and this was consistent with the electronics operating as expected up to the point of sail deployment. Sufficient and expected power was provided to the burn wire system. Sufficient and expected power was consumed by the cold gas generators used to inflate the mast, however the power profile for the motor during deployment was consistent with a stall condition and a repeated retry.

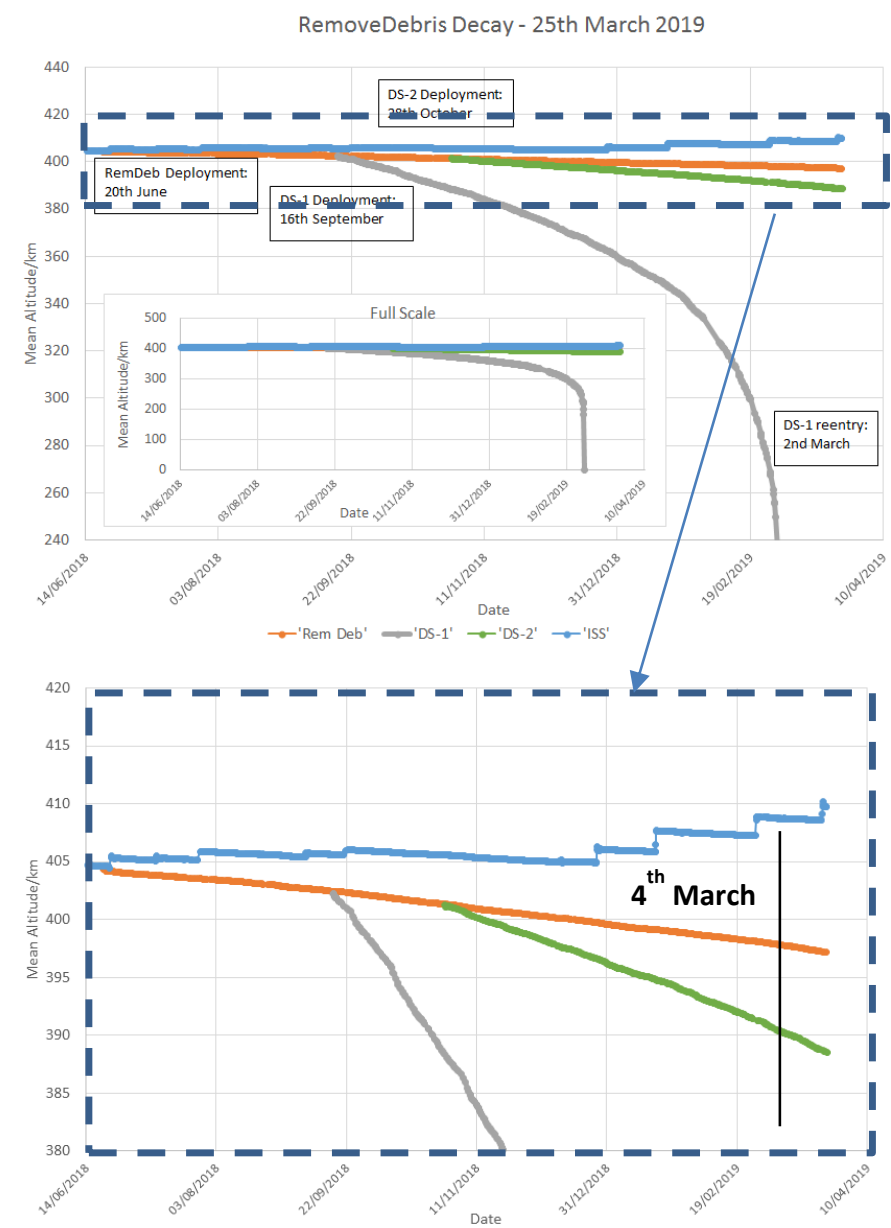

Figure 28: Top: orbital decay of the various elements of the RemoveDEBRIS mission. Bottom: detail of the curves highlighting ISS orbit raise maneuvers and decay of the CubeSat's and mothership

Some observations of the brightness of the object from ground telescope/radar showed some increase of brightness (the brightness fluctuates as it depends on the orientation of the object as it reflects the light, so accurate measurements are often difficult) but the increase in magnitude of the brightness was not consistent with a full deployment of the sail.

No significant changes in the power of the solar arrays or solar sensor signals were detected.

Finally the analysis of the altitude of the orbit of the object showed that there were no significant changes.

Figure 28 shows the $405 \mathrm{~km}$ altitude orbit of the ISS, the orbit of the mothercraft (slowly decaying and going from the $405 \mathrm{~km}$ at the moment of deployment from the ISS (20 June 2018) to $397 \mathrm{~km}$ at the end of March 2019), and the decaying orbits of the two cubesats. The orbit of DSAT\#1, separating from the mothercraft on the $18^{\text {th }}$ of September 2018, is coming down very quickly as the object produces significant drag (due to the deployable structure and being entangled by the net) so that the object re-entered in the atmosphere the $2^{\text {nd }}$ of March 2019. The initial prediction was the $4^{\text {th }}$ of March. The orbit of DSAT\#2 is also visible separating from that of the mothercraft on the $28^{\text {th }}$ of October 2018 and drifting down at a faster rate than the mothercraft, but not as quickly as DSAT\#1. The expectation was that deploying the dragsail on the $4^{\text {th }}$ of March 2018 from here the orbit of the mothercraft would started to decay more rapidly. However, no significant change is visible in the trajectory of the craft.

All the data available is consistent with a partial deployment or the sail not coming out from the container (see Figure 29). The device should have deployed like that shown in Figure 30.

At this stage it is not possible to say whether the issue was caused by the inflatable boom not deploying, and because the sail was still in its container the CFRP boom could not deploy (as constrained by the side walls of the container), or if the sail got tangled and therefore the CFRP booms could not extend as they were constrained by the sail.

\section{VI.1. DragSail further developments}

The lesson learned from the design, manufacturing, assembly and integration of the DragSAIL for RemoveDEBRIS were put into practice in the development of the DragSail for the InflateSAIL cubesat ([20] [21]) and two new dragsails that were designed and built for the Space Flight Industries for their SSO-A Mission [22].

Although the Dragsail for InflateSail was (successfully) 
activated at the end of June 2017 (deorbiting the cubsat from an orbit of approximately $500 \mathrm{~km}$ in approximately 3 months), which is well before the activation of the RemoveDEBRIS' dragsail, the mission benefitted from the lesson learned from the RemoveDEBRIS Dragsail development as well as improvements in the testing processes.

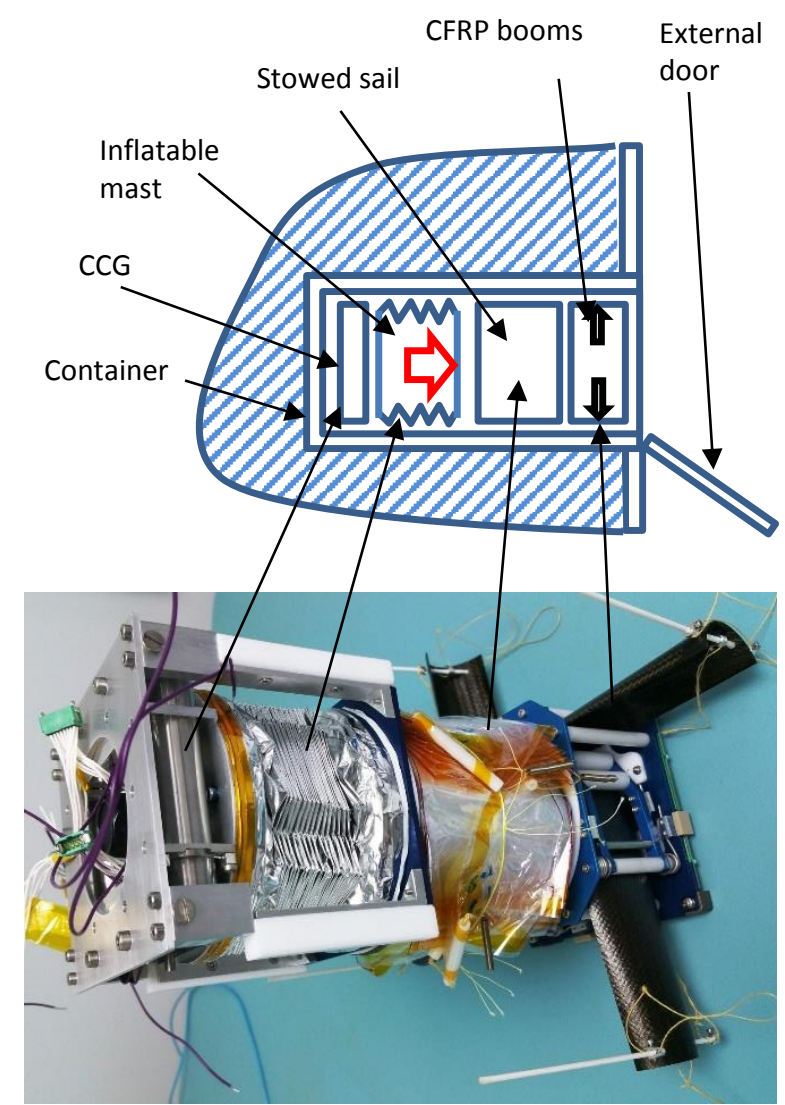

Figure 29: DragSail and schematic of the device in its container mounted on RemoveDEBRIS

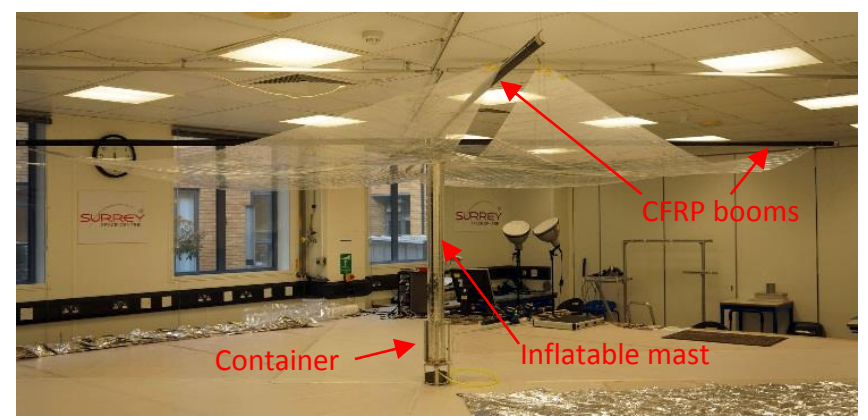

Figure 30: DragSail for InflateSAIL with inflatable mast and sail deployed

The two further Dragsails for the SSO-A mission also benefitted from the RemoveDEBRIS experience. In this case the assembly (shown in Figure 31) did not contain the inflatable boom, and proof of the successful deployment has been given by a significant increase of brightness of both craft that were equipped with the new DragSails, radar cross section, and by an enhanced drag effect. Note that in this mission, the mass of the craft and the altitude of the orbit are both much higher than those of RemoveDEBRIS, and therefore the effect on the orbit is not as pronounced as it would have been for RemoveDEBRIS. Re-entry of the first of the two craft expected in approximately three years.

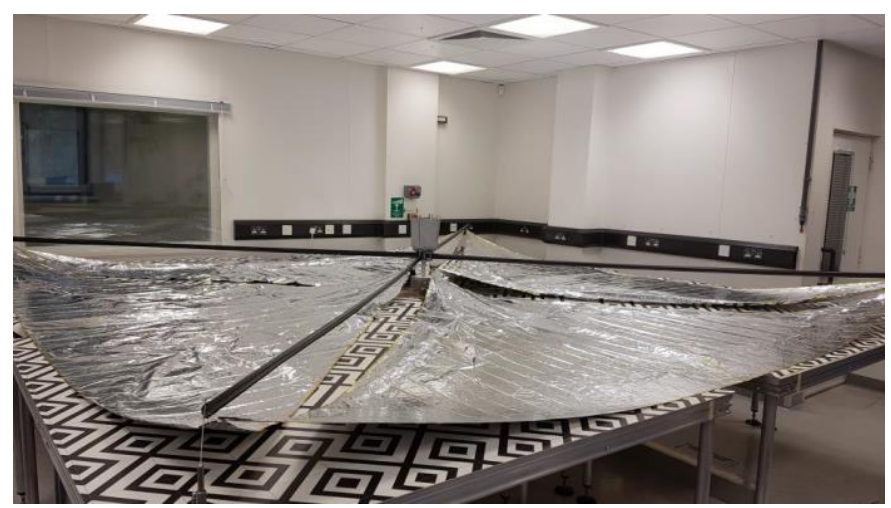

Figure 31: Deployment test of the DragSail for the SSO-A mission

\section{CONCLUSION}

RemoveDebris has been the first mission to perform successfully in-orbit demonstrations of technologies for active debris removal.

Released in orbit via the ISS, where the spacecraft was taken by the Space X Dragon Capsule during one of the periodic ISS resupply missions, RemoveDEBRIS has been the largest craft deployed so far from the ISS. The deployment utilized the Airlock in the Japanese Module of the ISS, and the craft was released by the KABER interface mounted on the Special Purpose Dexterous Manipulator (SPDM).

The first demonstration, the Net capture was successful. The Net tested, fully representative of the operational design, succeeded to capture the target cubsat that had inflated some structures to provide a more realistic representation (in terms of size) of a potential target space debris. There were some deviations from the expected behavior of some elements of the demonstrations, i.e. relatively fast spinning of the target and distance of the capture, however the images acquired have confirmed the proper working of the device. Indeed before using this technology for the capture of real large space debris the hardware will need scaling up and potentially modifications of mesh size or number of masses will be considered. Indeed once captured the debris will need to be secured to the mothercraft in order to be disposed of. 
This could be achieved by having the net tethered to the mothercraft in order for the debris to be actively towed (thus giving some control in the disposal), or slowed down by the action of a Dragsail on the mothercraft (without active control of the disposal). Further work will be necessary to verify the viability of these (or other) options for the disposal. However, what is important, is that the overall success of the demonstration, established this technology as a variable candidate for capturing large space debris.

The VBN cameras and algorithm performed very well, being the most computationally complex of the four demonstrations, the cameras acquired all the images expected of the target with different lighting conditions, background and range. The database of images collected and ground truth associated is unique, and of prime importance. It enabled us to assess the sensors robustness (camera \& Lidar) in real conditions and to assess algorithms performance and robustness for future non collaborative rendezvous on real images.

The harpoon capture experiment was also successful, with the device firing the harpoon with appropriate speed and this centering and capturing the target as planned. The target was snapped off of the supporting boom, floated away temporarily, retained by the tether line thus demonstrating the correct working of the harpoon \& tether concept. Also, this technology has been proven as viable for the capture of large space debris, and, as for the net, further investigations will be necessary to assess the best methodology for the following disposal of the debris that has been captured.

For the final experiment, the DragSail, the absence of monitoring cameras or detailed telemetry prevented complete conclusions on the cause and extent of the malfunction of the device. At the time, this was disappointing, however the lesson learned in developing the hardware has already been put into practice in another three devices (the InflateSail cubesat, and two DragSails provided to a commercial organization) that have been successfully demonstrated in orbit. Hence, as the ultimate purpose of the RemoveDEBRIS in flight demonstrations was to pave the way for industrial/commercial development and exploitation, also the last experiment can be considered successful as it enabled the development of commercial devices.

Besides the technical achievement RemoveDEBRIS has attracted significant media attention, and its various successes have been reported by all the major world news outlets. This has contributed to raise awareness of the issues in the public and policy makers, creating a momentum that hopefully it will help convince the relevant authorities to support the delivery of missions to remove the some of the large debris currently orbiting around the Earth.

\section{ACKNOWLEDGEMENTS}

This research is supported by the European Commission FP7-SPACE-2013-1 (project 607099) 'RemoveDebris A Low Cost Active Debris Removal Demonstration Mission', a consortium partnership project consisting of: Surrey Space Centre (University of Surrey), SSTL, Airbus GmbH, Airbus SAS, Airbus Ltd, Ariane Group, Innovative Solutions in Space (ISIS), CSEM, Inria, Stellenbosch University.

The consortium would like also to thank NanoRack for their support to the launch operations.

\section{REFERENCES}

[1] J. L. Forshaw, G. S. Aglietti, N. Navarathinam, H. Kadhem, T. Salmon, A. Pisseloup, E. Joffre, T. Chabot, I. Retat, R. Ax- thelm S. Barraclough, A. Ratcliffe, C. Bernal, F. Chaumette, A. Pollini, W. H. Steyn, RemoveDEBRIS: An in-orbit active debris removal demonstration mission, Acta Astronautica 127 (2016) 448 - 463 doi:10.1016/j.actaastro.2016.06.018.

[2] J. L. Forshaw, G. Aglietti, T. Salmon, I. Retat, M. Roe, C. Burgess, T. Chabot, A. Pisseloup, A. Phipps, C. Bernal, F. Chaumette, A. Pollini, W. H. Steyn, Final payload test re- sults for the RemoveDebris active debris removal mission, Acta Astronautica 138 (2017) 326 - 342. doi:10.1016/j.actaastro. 2017.06.003.

[3] J. L. Forshaw, G. S. Aglietti, T. Salmon, I. Retat,, A. Hall, T. Chabot, A. Pisseloup, D. Tye, C. Bernal, F. Chaumette, A Pollini, W. H. Steyn, "The active space debris removal mission RemoveDebris. Part 1: from concept to launch. Submitted to Acta Astonautica

[4] C. Saunders, J. L. Forshaw, V. J. Lappas, A. Chiesa, B. Parreira,R. Biesbroek, Mission and systems design for the debris removal of massive satellites, in: 65th International Astronautical Congress, Toronto, Canada, 2014.

[5] Forshaw, J. L., Massimiani, C., Richter, M., Viquerat, A., Simons, E., Duke, R. and Aglietti, G. S., "Surrey Space Centre: A Survey of Debris Removal Research Activities", 66th International Astronautical Congress, Jerusalem, Israel. 2015

[6] J. L. Forshaw, G. S. Aglietti, T. Salmon, I. Retat, M. Roe, T. Chabot, C. Burgess, A. Pisseloup, A. Phipps, C. Bernal,F. Chaumette, A. Pollini, W. H. Steyn, Review of final payload test results for the RemoveDebris active debris removal mission, in: 67th International Astronautical Congress, Guadalajara, Mexico, 2016.

[7] Forshaw, J. L., Aglietti, G. S., Salmon, T., Retat, I., Hall, A., Chabot, T., Pisseloup, A., Tye, D., Bernal, C., Chaumette, F., Pollini, A. and Steyn, W. H., "The RemoveDebris ADR Mission: Launch from the ISS, Operations and Experimental Timelines", 68th International Astronautical Congress, Adelaide, Australia 2017. 
[8] B. Taylor, Guglielmo S. Aglietti, S. Fellowes, T. Salmon, A. Hall, T. Chabot, A. Pisseloup, S. Ainley, D. Tye, I. Retat, C. Bernal, F. Chaumette, A. Pollini, W. Steyn, "RemoveDebris Preliminary Mission Results" International Astronautical Congress, IAC-18A6.1.5, Bremen, Germany 1-5 Oct 2018.

[9] Virgili, B., Lewis, H., Radtke, J., Krag, H., Revelin, B., Cazaux, C., ... Metz, M. (2016). Risk to space sustainability from large constellations of satellites. Acta Astronautica, 126, 154-162. DOI: 10.1016/j.actaastro.2016.03.034

[10] C. Bonnal, J.M. Ruault, M.C. Desjean, "Active debris removal: Recent progress and current trend" Acta Astronautica 85:51-60 . April 2013.

[11], C. Bonnal D. S. McKnight, "IAA Situation Report on Space Debris - 2016. International Academy of Astonautucs. May 2017

[12] L. Innocenti, Clean space - an overview, in: ESA Clean Space Industrial Days, ESTEC, Netherlands, 2016.

[13] Minghe Shan, Jian Guo, Eberhard Gill, "Review and comparison of active space debris capturing and removal methods" Progress in Aerospace Sciences, Volume 80, January 2016, Pages 18-32

[14]C. Rpiyant Mark, Surekha Kamath, "Review of Active Space Debris Removal Methods" Space Policy, 47 pp194- 206, 2019

[15] M.EmanuelliG.FedericoJ.LoughmanD.PrasadT.ChowM.Rathnas abapathy. "Conceptualizing an economically, legally, and politically viable active debris removal option" Acta Astronautica Volume 104, Issue 1, Pages 197-205, November 2014,

[16] T. Yamamoto, H. Okamoto, S. Kawamoto "Cost analysis of active debris removal scenarios and system architectures, 7th European Conference on Space Debris, At Darmstadt, Germany, April 2017

[17] Forshaw, J. L., Aglietti, G. S., Salmon, T., Retat, I., Burgess, C. , Chabot, T., Pisseloup, A., Phipps, A., Bernal, C., Chaumette, F., Pollini, A. and Steyn, W. H (2017), "The RemoveDebris ADR Mission: Preparing for an International Space Station Launch", 7th European Conference on Space Debris, ESA ESOC, Germany.

[18] Safety Review Process- International Space Station Program, NASA SSP 30599 Rev E June 2009

[19] NanoRacks, Space station CubeSat deployment services, Tech. rep. (February 2015).

[20] Underwood, C, Denis, A, Viquerat, AD, Taylor, B, Sanders, B, Stewart, B, Massimiani, C, Bridges, C, Masutti, D, Aglietti, G, Schenk, M, Duke, R \& Fellowes, S, 2019, 'InflateSail De-Orbit Flight Demonstration Results and Follow-On Drag-Sail Applications'. Acta Astronautica.

[21] Underwood, Craig, Viquerat, Andrew, Schenk, Mark, Taylor, Ben, Massimiani, Chiara, Duke, Richard, Stewart, Brian, Fellowes, Simon, Bridges, Chris, Aglietti, Guglielmo et al (2018) InflateSail De-Orbit Flight Demonstration Results and Follow-On Drag-Sail Applications In: 69th International Astronautical Congress (IAC), 01-05 Oct 2018, Bremen, Germany.

[22] SSO-A mission update: upper and lower free flyers deorbiting as planned - press release http://spaceflight.com/sso-a-missionupdate-upper-and-lower-free-flyers-deorbiting-as-planned/ 